\title{
COMMISSION 14: ATOMIC AND MOLECULAR DATA
}

\section{(DONNEES ATOMIQUES ET MOLECULAIRES)}

\author{
PRESIDENT: W. H. PARKINSON \\ VICE PRESIDENT: F. ROSTAS \\ oRGANIZING COMMITTEE: S. J. Adelman, J. Dubau, N. Grevesse, S. Johansson, U. Jorgenson \\ H. Mason, F. Rostas, W.-ÜL. Tchang-Brillet, P. L. Smith, \\ and W. L. Wiese
}

As a result of the deliberations and discussions during the last General Assembly of the IAU in The Hague, it was recommended that Commission 14 become a commission of the Executive Committee. The special interdisciplinary role and nature of Comm. 14 were in this way recognized and encouraged.

Comm. 14 fulfills its role by informing the astronomical community of new developments in our various fields though specific involvement and support of IAU Symposia and Joint Discussions, and by the Reports of the Working Groups. The symposia and JDs are especially important means by which we acquire and provide information on the needs for, and availability of, atomic and molecular data. The most recent such example, co-supported by Comm. 14, was IAU Symposium 178, Molecules in Astrophysics: Probes \&3 Processes, July 1-5, 1996, Leiden, The Netherlands. During the IAU General Assembly in Kyoto, Japan, August 18-30, 1997, Comm. 14 will co-support Symposium 188, The Hot Universe; JD4, Challenges in Atomic Physics for Cosmic X-Ray Spectroscopy; JD16, Spectroscopy with Large Telescopes on Chemical Pecular Stars; and JD12, Electronic Publishing Now and the Future.

The reports from the Working Groups appear below where the highlights and triennial references of activities are given. The reference lists always have added value because of the expert selectivity of WG Chairs. For these triennial reports, the scope of the references have been expanded by the Chairs to include URLs of databases for atomic and molecular data. In order to make the WG reports more generally accessible, we have made them available on-line from the Comm. 14 WWW Home Page (http://cfa-ww. harvard. edu/amp/iau14/).

We express very best wishes and encouragement to Dr. Jean Gallagher and I thank Dr. Dave Schultz for preparing and writing, with little notice, the WG3 report.

\section{WORKING GROUP 1: ATOMIC SPECTRA AND WAVELENGTHS STANDARDS W. C. Martin, Chair}

The references cited for all categories of data in this report comprise a supplement for the period 1993-1996 to two previous reports: (1) the 1994 report of this working group covering the period 1991-1993, and (2) an extensive review of atomic spectroscopic data for astrophysics covering the literature to 1991 (Martin 1992).

\section{Energy-Level Analyses, Wavelengths and Line Classifications}

The references cited in this section are mostly papers on original laboratory research; recent larger compilations are covered in another section. The references, ordered by atomic number and spectrum, are given in parentheses following the spectra notations. They are designated by the first letter of the 
first author's last name and a serial number; these designations precede the full citations in the reference list at the end of this report.

Li I (R5); Be I (K1); [N II] (B5, S3), N v1 (E2); O vil (E2); Ne I (C1), Ne II (Q1); Al X (K2); [Si I] (B8), Si III (S1), Si xI (K4, K2); [P II] (B6); [S I] (B9), S VII (B1), S xIII (K2), S xv (H1); Ar II (P2, Q2), Ar IV (B4), Ar X (B2), Ar XV (K2); K II (V1); Ca III (V1); Ti XIII (J1); Fe I (N2, N3, J2, B7), Fe II (N1, B3), Fe III (E1), Fe vi (A1), Fe xxIV (R3); Co I (P1), Co vil (R6); Ni I (L2), Ni xxIv (M1); Zr III (R4); Pd II (L1); Dy III (S2); Er I (K3); Pt III (R1); Au II (R2), Au III (W2), Au IV (W1), U II (B10).

The references for elements heavier than $\mathrm{Ni}(Z>28)$ are limited to the first three or four spectra only, these data being of interest for solar and/or stellar spectroscopy, especially for chemically peculiar stars. The references for the lighter elements are also incomplete, the selection being limited to those of highest astrophysical interest. The data in a number of the references include and/or supersede all or most of the previously available energy-level and wavelength data for the indicated spectrum; such references include those for Be I (a compilation), Si XI (K1), S viII, Ar IV, Ti III, Fe I (N2), Fe xxiv, Co I, Ni I, Dy III, Pt III, and Au II. In a paper not cited above, Kelly and Lacy (1995) give accurate wavenumbers for fine-structure transitions in nine spectra ([Ne v] to $[\mathrm{Fe} \mathrm{II}]$ ) as determined from astronomical observations in the mid-infrared region. With regard to the iron-group elements, laboratory work is now underway on T'i II, V I, Cr III, Mn II, Fe II, Fe III, Fe V, Fe VI, and Co II; much of this research is being carried out. at the University of Lund, Sweden, with additional work at Imperial College, London (Fe III and Co II), the Universities of Liège and Mons-Hainaut (V I), and the Observatoire de Paris (Mn II).

\section{Wavelength Standards}

Nave et al. (1996) have determined very high-accuracy Ritz wavelengths for 473 vacuum-ultraviolet Fe It lines $(927-1995 \AA)$. They recommend the new values as standards, the uncertainties lying mainly in the range 0.0001 to $0.0003 \AA$. These new Fe II standards, like several sets of high-accuracy wavelength determinations cited in our previous reports, depend on visible-region Ar II reference standards from Norlén (1973). New measurements of the Ar spectrum from a hollow-cathode discharge by Whaling et al. (1995) give Ar II wavenumbers systematically greater than Norlén's values by about 7 parts in $10^{8}$; adjustment of the new Fe II results of Nave $e t$ al. to the Ar II wavenumber values of Whaling $e t$ al. would decrease the Fe II wavelengths by 0.00006 to $0.00014 \AA$.

The paper by Whaling et al. gives high-precision Ritz wavelengths for hundreds of Ar II lines over the range $2225 \AA$ to $5.33 \mu \mathrm{m}$. The wavenumber uncertainties of most of the lines are less than $0.001 \mathrm{~cm}^{-1}$, but the values are uncorrected for any pressure shifts. A number of the lines in the range $3600 \AA$ to $3.27 \mu \mathrm{m}$ are indicated as especially appropriate for use as reference standards because of their small pressure shifts. The systematic disagreement of 7 parts in $10^{8}$ between these $\mathrm{Ar}$ II wavenumber determinations and those by Norlén "is roughly twice the uncertainty assigned to the wavenumbers in either experiment" (Whaling et al. 1995). The indicated need for additional measurements is, according to Nave et al., being met by experiments underway in other laboratories.

\section{Larger Compilations, Reviews, Conference Proceedings}

The atomic data for absorption lines compiled by Verner et al. (1994) include data for 2249 lines having wavelengths greater than $228 \AA$. Shirai et al. (1996b) have completed a large single-volume tabulation of spectral-line data for highly-ionized atoms of $\mathrm{Ti}$ through $\mathrm{Cu}$, and $\mathrm{Kr}$ and $\mathrm{Mo}$. The energy levels of the Zn spectra ( $\mathrm{n}$ I-XXX) have been compiled (Sugar and Musgrove, 1995), and a new compilation of data for the Ga spectra ( $\mathrm{Ga}$ I-XXXI) includes classified lines and separate tables of energy levels (Shirai et al. $1996 \mathrm{a})$. 
The data in most of the newly published major compilations of these types are now also available via the Internet; for example, all of the above compilations except the absorption-line data are accessible at the NIST Physics Laboratory Web site, and the absorption data are included in the holdings of the "Atomic Data for Astrophysics" site (see below for the addresses of Web sites mentioned in this paragraph). It is also worth noting that some of the newly compiled or updated data being loaded into Internet databases may not be published in printed form. The energy-level data for the $\mathrm{C}, \mathrm{N}$, and $\mathrm{O}$ spectra in the NIST database for example, include some updating of the older compilations. Quite large datasets previously available only on magnetic tape or CD-ROM's have also been made available via the Internet, examples being the Kurucz CD-ROM 23 (CfA site, see Smith et al. 1996) and the "Atomic Spectral Line List" of R. Hirata and T. Horaguchi (CDS site, Catalogue VI/69). The "Vienna Atomic Line Data Base" is accessible only via e-mail (Piskunov et al. 1995).

A number of papers on atomic spectroscopic data are included in the proceedings of a workshop on Laboratory and Astronomical High Resolution Spectra (Sauval et al. 1995), and a few such papers were given at an IAU Joint Discussion on Astrophysical Applications of Powerful New Databasts (Adelman and Wiese 1995). The invited papers given at the Fifth International Colloquium on Atomic Spectra and Oscillator Strengths for Astrophysical and Laboratory Plasmas, held in Meudon, France, August 1995, are scheduled for publication (Tchang-Brillet et al. 1996a). Many of the contributed papers for this colloquium were on particular spectra of astrophysical interest; these appear in a publication of the Paris Observatory (Tchang-Brillet et al. 1996b).

\section{Atomic Spectroscopic Data on the Internet}

The amount of atomic and molecular data conveniently available via the Internet has greatly increased very recently (since early 1995). The URL addresses for a number of World Wide Web sites offering laboratory data of the types covered by Working Groups 1 and 2 are listed below. The italicized names of particular databases or datasets are followed by symbols CL, EL, TP in parentheses, indicating types of data:

CL Experimental wavelengths given with energy-level classifications.

EL Experimental values for energy levels.

TP Transition probabilities and/or related quantities (oscillator strengths, etc.).

Unless otherwise indicated, the italicized names represent hypertext links that yield the data directly online. No detailed descriptions of the holdings or other features of the databases are given; since most of the databases are under development, even the minimal information provided here may in some cases be out of date by the time this report is published. The list includes only databases that offer one or more of the above three types of data and, even so, is not complete. A Weizmann Institute site (see below) maintains an updated hypertext list of atomic databases and datasets on the Internet.

Databases for Atomic and Plasma Physics (Weizmann Inst. of Science, Israel) http://plasma-gate.weizmann.ac.il/DBfAPP.html

This site has links to most of the databases listed here as well as to a number of others. Links to new databases are added as they come online. Instructions are given for e-mail access to data from the Vienna Atomic Line Data-Base (CL, T'P) and for ftp downloading of a Spectral Bibliography Database (BIBL), developed and maintained by the Institute of Spectroscopy, Russia.

CDS (Centre de Donnes astronomiques de Strasbourg, France)

http://cds-web.u-strasbg.fr

Select Catalogues and VI Miscellaneous (CL, EL, TP) and choose from a list of catalogues including several with extensive atomic spectroscopic data. Items from journals (journal title) include additional 
catalogues with atomic spectroscopic data. Some catalogues are searchable (use VizieR), others accessible only via ftp. Select TOPbase (TP) and make a telnet connection to a database system incorporating data from the Opacity Project. Topbase data files can be transferred via ftp.

\section{Astronomical Data Center (NASA Goddard Space Flight Center, U.S.A.)} http://adc.gsf .nasa.gov

Select $A D C$ 's Archives (CL, EL, TP). Archives include extensive files of atomic spectroscopic data, having a large overlap with the CDS catalogues (see above) and other CDS holdings. Items of interest can be identified by online keyword searches, but data are accessible only via ftp. Site also has lists of contents of $\mathrm{ADC}$ CD-ROM's, one of which includes atomic spectroscopic data (CL, EL, TP).

WWW Server in NAOJ/ADAC (National Astronomical Observatory, Japan) http://adac.mtk.nao.ac.jp

The Clickable list of the catalogs and Miscellaneous Data (CL, EL, TP) yield a list including the CDS catalogues (see above). Data are transferred via ftp.

NIST Physics Laboratory (National Institute of Standards and Technology, U .S.A) http://physics.nist.gov

Select Physical Reference Data and Atomic Spectroscopic Database (CL, EL, TP), a component of the NASA Astrophysics Data System; also Spectrum of Platinum Lamp (CL) and Bibliographic Database on Atomic Transition Probabilities. Site has other atomic databases, and also molecular databases of astrophysical interest.

CfA Atomic and Molecular Physics Division (Harvard-Smithsonian Center for Astrophysics) http://cfa-www.harvard.edu/amp

Select Databases and Kurucz CD-ROM 18, Kurucz CD-ROM 23 (CL, TP) or R. L. Kelly (CL). Links to some other sites (Smith et al. 1996).

Atomic Data for Resonance Absorption Lines (Herzberg Inst. of Astrophysics, Canada)

http://wwr.dao.nrc.ca/ dcm/atomic_data.html

Select from several files (CL, TP) including finding lists (Morton 1991, with updating).

Atamic Data for Astrophysics (University of Kentucky, U.S.A)

http://www.pa.uky . edu/ verner/atom.html

Select Energy Levels, Wavelengths, Transition Probabilities (CL, TP). Data for resonance and absorption lines (Verner et al. 1994). Links to a number of other databases or datasets, mainly CDS catalogues.

SAM Project (NASA Goddard Space Flight Center, U.S.A.)

http://aniara.gsfc.nasa.gov/sam.html

Lists of Results (CL, TP) are sorted according to types of data, including calculated oscillator strengths. Some of the files are accessible via ftp only.

An atomic spectroscopic database being developed as a Web site at the University of Lund, Sweden, is expected to go online during 1997. The URL: http://Rydberg.fysik.lu.se.

\section{References}

Adelman, S. J., Wiese, W. L., Eds., 1995. Astron. Soc. Pac. Conf. Proc. 78, 546pp.

A1 Azarov, V. I., Podobedova, L. I., Ryabtsev, A. N., 1996. Phys. Scr. 53, 398-413.

B1 Bengtsson, P., et al., 1993. Phys. Scr. 48, 413-424.

B2 Bengtsson, P., Engström, L., Jupén, C., 1994. Phys. Scr. 49, 297-302.

B3 Biémont, E., Johansson, S., Palmeri, P., 1996. Phys. Scr., submitted.

B10 Blaise, J., et al., 1994. J. Opt. Soc. Am. 11, 1897-1929. 
B4 Bredice, F., et al., 1995. Phys. Scr. 51, 446-453.

B5 Brown, J. M., et al., 1994. Astrophys. J, 428, L37-L40.

B6 Brown, J. M., et al., 1996. Astrophys. J. 464, L203-L206.

B7 Brown, J. M., Evenson, K.M., 1995. Astrophys. J. 441, L97-L100.

B8 Brown, J. M., Zink, L. R., Evenson, K. M., 1994. Astrophys. J. 423, L151-L154.

B9 Brown, J. M., Zink, L. R., Evenson, K. M., 1994. Astrophys. J. 431, L147-L149.

C1 Chang, E. S., et al., 1994. Phys. Scr. 49, 26-33.

E1 Ekberg, J. O., 1993. Astron. Astrophys. Suppl. Ser. 101, 1-36.

E2 Engström, L., Litzén, U., 1995. J. Phys. B 28, 2565-2574.

H1 Howie, D. J. H., Silver, J. D., Myers, E. G., 1996. J. Phys. B 29, 927-936.

J2 Johansson, S., et al., 1994. Astrophys. J. 429, 419-426.

J1 Jupén, C., Litzén, U., Träbert, E., 1996. Phys. Scr. 53, 139-148.

Kelly, D. M., Lacy, J. H., 1995. Astrophys. J. 454, L161-L164.

K2 Khardi, et al, 1994. Phys. Scr. 49, 571-577.

K1 Kramida, A. E., Martin, W. C., 1997. J. Phys. Chem. Ref. Data 26.

K4 Kramida, A. E., Träbert, E., 1995. Phys. Scr. 51, 209-226.

K3 Kronfeldt, H.-D., et al., 1993. Phys. Scr. 48, 688-698.

L2 Litzén, U., Brault, J. W., Thorne, A. P., 1993. Phys. Scr. 47, 628-673.

L1 Lundberg, H., Litzén, U., Johansson, S., 1994. Phys. Scr. 50, 110-118.

Martin, W. C., 1992. Lecture Notes in Physics 407, 121-147. Chapter 8 in Smith, P. L., Wiese, W. J., (Eds.) Atomic and molecular data for space astronomy. Berlin: Springer-Verlag. Morton, D. C., 1991. Astrophys. J., Suppl. Ser. 77, 119-202.

M1 Myrnäs, R., et al., 1994. Phys. Scr. 49, 429-435.

N3 Nave, G., et al., 1994a. Phys. Scr. 49, 581-587.

N2 Nave, G., et al., 1994b. Astrophys. J., Suppl. Series 94, 221-459.

N1 Nave, G., Johansson, S., Thorne, A. P., 1996. J. Opt. Soc. Am. B, accepted. Norlén, G., 1973. Phys. Scr. 8, 249-269.

P2 Palmeri, P., Biémont, E., 1996. Phys. Scr. 51, 76-80.

P1 Pickering, J. C., Thorne, A. P., 1996. Astrophys. J., in press. Piskunov, N. E., et al., 1995. Astron. Astrophys. Suppl. Ser. 112, 525-535.

Q1 Quinet, P., Palmeri, P., Biémont, E., 1994. Phys. Scr. 49, 436-445.

Q2 Quinet, P., et al., 1994. Phys. Rev. A 49, 2446-2452.

R5 Radziemski, L. J., Engleman, R., Jr., Brault, J. W., 1995. Phys. Rev. A 52, 4462-4470.

R3 Reader, J., et al., 1994. J. Opt. Soc. Am. B 11, 1930-1934.

R4 Reader, J., Acquista, N., 1996. Phys. Scr., in press.

R2 Rosberg, M., Wyart, J. F., 1996. Phys. Scr., in press.

R6 Ryabtsev, A. N., 1994. Opt. Spectrosc. 76, 199-209.

R1 Ryabtsev, A. N., et al., 1993. Phys. Scr. 47, 45-58.

Sauval, A. J., Blomme, R., Grevesse, N., Eds., 1995. Astron. Soc. Pac. Conf. Proc. 81, 646pp.

S1 Sayyad, M. H., et al., 1995. J. Phys. B 28, 1715-1722.

Shirai, T., Sugar, J., Musgrove, A., 1996a. J. Phys. Chem. Ref. Data, submitted.

Shirai, T., Sugar, J., Wiese, W. L., 1996b. J. Phys. Chem. Ref. Data Monogr. 8, in press.

Smith, P. L., et al., 1996. See Tchang-Brillet et al., $1996 \mathrm{~b}$.

S2 Spector, N., Sugar, J., Wyart, J.-F., 1996. J. Opt. Soc. Am. B.

S3 Spyromilio, J., 1995. Mon. Not. R. Astron. Soc. 277, L59-L62.

Sugar, J., Musgrove, A., 1995. J. Phys. Chem. Ref. Data 24, 1803-1872.

Tchang-Brillet, W.-ÜL., Wyart, J.-F., Zeippen, C. J., Eds., 1996a. Phys. Scr. T65.

Tchang-Brillet, W.-ÜL., Wyart, J.-F., Zeippen, C. J., Eds., 1996b. "Poster Papers," Publication Speciale de l'Observatoire de Paris, Meudon.

V1 van Kampen, P., et al., 1995. J. Phys. B 28, 4771-4779.

Verner, D. A., Barthel, P. D., Tytler, D., 1994. Astron. Astrophys. Suppl. Ser. 108, 287-340.

Whaling, W., et al., 1995. J. Quant. Spec. Rad. Transfer 53, 1-22.

W1 Wyart, J.-F., et al., 1994. Phys. Scr. 50, 672-695.

W2 Wyart, J.-F., et al., 1996. Phys. Scr. 53, 174-196.

\section{WORKING GROUP 2: ATOMIC TRANSITION PROBABILITIES}

\section{W. L. Wiese, Chair}

The Data Center on Atomic Transition Probabilities at the National Institute of Standards and Technology (NIST) Gaithersburg, MD 20899, USA is continuing its critical data compilation work and is also participating in the development of a comprehensive atomic spectroscopic database of which a first version is installed on the World Wide Web. This database may be accessed from the NIST Physics 
Laboratory WWW homepage at http://physics.nist.gov/. Further details on this and several other alomic spectroscopic databases on the Internet are given in the report of Working Group 1.

The comprehensive NIS'T bibliographical database, which now contains more than 6,600 entries, has been updated through June 1996 and is also available at the above cited World Wide Web site.

The current compilation work of the NIST atomic transition probabilities data center is centered on the evaluation and tabulation of numerical data for the lighter elements. Work is in progress on hydrogen, helium, lithium, beryllium, boron, fluorine, neon, sodium, and magnesium. The tabulations include allowed (electric dipole) as well as forbidden (mainly magnetic dipole and electric quadrupole) lines.

Some major works on transition probability and lifetime data during the last three years are the following:

(a) In early 1996, the NIST data center published a 532-page volume of critically evaluated transition probabilities for the three elements carbon, nitrogen and oxygen as Monograph No. 7 of the Journal of Physical and Chemical Reference Data. This volume contains about 12,500 transitions for all 21 spectra of these three elements.

(b) A large amount of data resulting from the Opacity Project and its successor, the Iron Project, has been published. For example, very extensive sophisticated calculations of transition probabilities for various ions of iron $[4,69,75,76,78,87]$ have been undertaken.

(c) Systematic and accurate multi-configuration calculations of transition probability data have been undertaken by a group of theoreticians under the leadership of Froese Fischer, Hibbert, and Brage (members of the SAM-project). This group maintains a World Wide Web site (address: http://aniara.gsfc.nasa.gov/sam/sam.html) from which new results are available.

(d) A large review concemed with data for lines starting from the ground states of many atoms and ions has been published by Verner et al. [102] Their listings contain 2,249 spectral lines, and the data are drawn mostly from the Opacity Project and recent critical compilations.

(e) Another review of neutral line oscillator strengths has been published by Doidge [34]. This compendium contains oscillator strengths for neutral atomic resonance lines of 65 elements and has been collected mostly for the needs of laboratory atomic absorption spectroscopy.

(f) A new edition of "Astrophysical Quantities" prepared by Cowley et al. [31], contains oscillator strength tables for about 500 prominent lines of astrophysical interest.

(g) Finally, it is of interest to note that a number of informative review articles on the status and accuracy of oscillator strength data were given at the 5th International Colloquium on Atomic Spectra and Oscillator Strengths for Astrophysical and Laboratory Plasmas, the proceedings of which are in preparation (see Tchang-Brillet [98]).

The remaining part of this report is a bibliography of selected recent literature references which contain new transition probability data of astrophysical interest produced during the last three-year period. Thus, this new selected bibliography continues where the last working group report left off. As in the previous reports, the bibliographical material is ordered with respect to element and state of ionization. Table 1 provides an overview of the bibliographical data by spectrum. The references are identified by a running number which refers to the general reference list at the end of this report. In the general reference list the literature is ordered alphabetically according to first author, and each reference contains one or more code letters indicating the method applied by the authors. These code letters are defined as follows:

\section{THEORETICAL METHODS:}

Q - quantum mechanical calculations.

CA - Coulomb approximation

\section{EXPERIMENTAL METHODS:}

F - measurements in emission (arc, furnace, discharge tube, shock tube, etc.).

A - measurements in absorption (King furnace, absorption tube, etc.).

$\mathrm{L}$ - lifetime measurements (including Hanle effect).

M - miscellaneous experimental methods (for example, Stark effect, astrophysical measurements, etc.). 


\section{OTIIER:}

$\mathrm{CP}$ - data compilation.

$\mathrm{R}$ - relative (non-absolute) been determined.

F - data on forbidden (i.e. other than electric dipole) transitions have been determined.

\section{References}

1. Adelman, S. J., Wiese, W. L. (Eds.): Astrophysical Applications of Powerful New Databases, ASP Conference Series, 78. San Francisco: Astron. Soc. of the Pacific (1995).

2. Anderson, H. M., Bergeson, S. D., Doughty, D. A., Lawler, J. E.: Phys. Rev. A 51, 211 (1995). A

3. Bard, A., Kock, M.: Astron. Astrophys. 282, 1014 (1994). E

4. Bautista, M. A., Pradhan, A. K.: Astron. Astrophys., Suppl. Ser. 115, 551 (1996). Q

5. Bengtsson, P., Curtis, L. J., Henderson, M., Irving, R. E.., Maniak, S. T.: Phys. Scr. 52, 506 (1995). L

6. Bergeson, S. I., Lawler, J. E.: Astrophys. J. 408, 382 (1993). E, L

7. Bergeson, S. D., Lawler, J. E.: Astrophys. J, 414, L137 (1993). L

8. Bergeson, S. D., Mullman, K. L., Lawler, J. E.: Astrophys. J. 435, L157 (1994). E

9. Bertuccelli, G., Di Rocco, H. O.: J. Quant. Spectrosc. Radiat. Transfer 55, 463 (1996). ER

10. Biemont, E., Delahaye, F., Zeippen, C. J.: J. Phys. B 27, 5841 (1994). Q

11. Biemont, E., Hansen, J. E., Zeippen, C. J.: Astrophysical Applications of Powerful New Databases, ASP Conference Series 78, 157-160 (1995). QF

12. Biemont, E., Gebarowski, R., Zeippen, C. J.: Astron. Astrophys. 287, 290 (1994). Q

13. Biemont, E., Martin, F., Quinet, P., Zcippen, C. J.: Astron. Astrophys. 283, 339 (1994). Q

14. Biemont, E., Quinet, P., Zeippen, C. J.: Astron. Astrophys. Suppl. Ser. 102, 435 (1993). Q

15. Bizzarri, A., Huber, M. C. F., Noels, A., Grevesse, N., Bergeson, S. D., Tsekeris, P., Lawler, J. E.: Astron. Astrophys. 273, 707 (1993). E, L

16. Bogdanovich, P. O., Zukauskas, G. L., Momkauskaite, A. P., Tutlys, V. I.: Sov. Phys.-Collect. 25, 33 (1985). Q

17. Brage, T., Froese Fischer, C.: Phys. Scr. T47, 18 (1993). Q

18. Brage, T., Froese Fischer, C., Jonson, P.: Phys. Rev, A 49, 2181 (1994). Q

19. Brage, T., Froese Fischer, C., Vaeck, N., Godefroid, M., Hibbert, A.: Phys. Scr. 48, 533 (1993). Q

20. Brage, T., Leckrone, D. S., Froese Fischer, C.: Phys. Rev. A 53, 192 (1996). Q

21. Brostroem, L., Mannervik, S., Passian, A., Sundstroem, G.: Phys. Rev. A 49, 3333 (1994). L

22. Butler, K., Mendoza, C., Zeippen, C. J.: J. Phys. B 26, 4409 (1993). Q

23. Cai, W., Pradhan, A. K.: Astrophys. J., Suppl. Ser. 88, 329 (1993). Q, QF

24. Caiyan, L., Berzinsh, U., Zerne, R., Svanberg, S.: Phys. Rev. A 52, 1936 (1995). L

25. Calamai, A. G., Smith, P. L., Bergeson, S. D.: Astrophys. J. 415, L59 (1993). E, L

26. Cardelli, J. A., Savage, B. D.: Astrophys. J. 452, 275 (1995). M

27. Carlsson, J., Joensson, P., Sturesson, L., Froese Fischer, C.: Phys. Rev. A 49, 3426 (1994). Q

28. Chen, M.-K.: J. Phys. B 27, 865 (1994). Q

29. Chen, M.-K.: J. Phys. B 27, 4847 (1994). Q

30. Connerade, J.-P., Schmidt, C., Warken, M.: J. Phys. B 26, 3459 (1993). Q

31. Cowley, C. R., Wiese, W. L., Fuhr, J. R., Kuznetsova, L. A. (in press, to be published in 1997). Astrophysical Quantities, 4th Edition, Ch. 4. A. N. Cox(Ed.) AIP Press. CP

32. Crespo Lopez-Urrutia, J. R., Ulbel, M., Neger, T., Jager, H.: J. Quant. Spectrosc. Radiat. Transfer 52, 89 (1994). E

33. Di Rocco, H. O.: Opt. Pura Apl. 21, 1 (1988). Q

34. Doidge, P. S.: Spectrochim. Acta, Part B 50, 209 (1995), errata: 50, 1421 (1995), 51, 375 (1996). CP

35. Drozdowski, R., Kwela, J., Walkiewicz, M.: Z. Phys. D 27, 321 (1993). L

36. Ekberg, J. O., Feldman, U.: Astrophys. J., Suppl. Ser. 86, 611 (1993). M

37. Engelke, D., Bard, A., Kock, M.: Z. Phys. D 27, 325 (1993). L

38. Fang, Z, Kwong, V. H. S, Parkinson, W. H.: Astrophys. J 413, L141 (1993). L

39. Fang, Z., Kwong, V. H. S., Wang, J., Parkinson, W. H.: Phys. Rev. A 48, 1114 (1993). L

40. Federman, S. R., Cardelli, J. A.: Astrophys. J. 452, 269 (1995). M

41. Fleming, J., Bell, K. L., Hibbert, A., Vaeck, N., Godefroid, M. R.: Mon. Not. R. Astron. Soc. 279, 1289 (1996). Q, QF

42. Fleming, J., Brage, T., Bell, K. L., Vaeck, N., Hibbert, A., Godefroid, M. R., Froese Fischer, C.: Astrophys. J. 455, 758 (1995). Q, QF

43. Fleming, J., Hibbert, A.: Phys. Scr. 51, 339 (1995). Q

44. Fleming, J., Vaeck, N., Hibbert, A., Bell, K. L., Godefroid, M. R.: Phys. Scr. 53, 446 (1996). Q

45. Fritzsche, S., Grant, I. P.: Phys. Lett. A 186, 152 (1994). Q

46. Froese Fischer, C.: Phys. Scr. 49, 51 (1994). Q

47. Froese Fischer, C.: Z. Phys. D 32, $21(1994)$. Q

48. Fuhr, J. R., Wiese, W. L. 1996. CRC Handbook of Chemistry and Physics, 77th Edition, Ch. 10, D. R. Lide and H. P. R. Frederikse (Eds), Boca Raton, Florida: CRC Press, 128-186. CP

49. Gibson, N. D., Risley, J. S.: Phys. Rev. A 52, 4451 (1995). A

50. Godefroid, M., Olsen, J., Joensson, P., Froese Fischer, C.: Astrophys. J. 450, 473 (1995). Q

51. Gonzalez, A. M., Ortiz, M., Campos, J.: J. Quant. Spectrosc. Radiat. Transfer 50, 35 (1993). E 
52. Cionzalez, A. M., Ortiz, M., Campos, J.: Can. J. Phys. 72, 57 (1994). E

53. Heise, C., Smith, P. L., Calamai, A. G.: Astrophys. J. 451, L41 (1995). L

54. Henderson, M., Bengtsson, P., Corcoran, J., Curtis, L. J., Irving, R. E., Maniak, S. T.: Phys. Scr. 53, 309 (1996). L

55. Hibbert, A., Hansen, J. E.: J. Phys. B 27, 3325 (1994). Q

56. Hoeling, B., Yeh, J. R., Takekosli, T., Knize, R. J.: Opt. Lett. 21, 74 (1996). L

57. Jin, J., Church, D. A.: Phys. Rev. Lett. 70, 3213 (1993). L

58. Jin, J., Church, D. A.: Phys. Rev. A 49, 3463 (1994). L

59. Johansson, S., Brage, T., Leckrone, D. S., Nave, G., Wahlgren, G. M.: Astrophys. J. 446, 361 (1995). CP, M

60. Keenan, F. P., Hibbert, A., Ojha, P. C., Conlon, E. S.: Phys. Scr. 48, 129 (1993). QF

61. Knauer, J.P., Kock, M.: J. Quant. Spectrosc. Radiat. Transfer 51, 723 (1994). E

62. Kroetz, W., Ulrich, A., Ribitzki, G., Wieser, J., Murnick, D. E.: Hyperfine Interactions 88, 193 (1994). L

63. Kwong, V. H. S., Fang, Z., Gibbons, T. T., Parkinson, W. H., Smith, P. L.: Astrophys. J. 411, 431 (1993). L

64. Langhans, G., Schade, W., Helbig, V.: Z. Phys. D 34, 151 (1995). L

65. Larsson, J., Meve, E., Zerne, R., L'Huillier, A., Wahlstroem, C.-G., Svanberg, S.: J. Phys. B 28, L53 (1995). L

66. Lee, K., Goo, J. S., Ku, J. K.: Chem. Phys. Lett. 216, 483 (1993). L

67. Liaw, S. S.: Can. J. Phys. 70, 1279 (1992). Q

68. Lowe, R. M., Biemont, E.: J. Phys. B 27, 2161 (1994). L, Q

69. Lynas-Gray, A. E., Seaton, M. J., Storey, P. J.: J. Phys. B 28, 2817 (1995). Q

70. Maniak, S. T., Curtis, L. J., Irving, R. F., Martinson, I., Helborg, R.: Phys. Lett. A 182, 114 (1993). L

71. Mende, W., Kock, M.: J. Phys. B 29, 655 (1996). M

72. Mendoza, C., Eissner, W., Le Dourneuf, M., Zeippen, C. J.: J. Phys. B 28, 3485 (1995). Q

73. Meylan, T., Furenlid, I., Wiggs, M. S., Kurucz, R. L.: Astrophys. J. Suppl. Ser. 85, 163 (1993). M

74. Molino Garcia, J. C., Boetticher, W., Kock, M.: J. Quant. Spectrosc. Radiat. Transfer 55, 169 (1996). A

75. Nahar, S. N.: Astron. Astrophys. 293, 967 (1995). Q

76. Nahar, S. N.: Phys. Rev, A 53, 1545 (1996). Q

77. Nahar, S. N., Pradhan, A. K.: J. Phys. B 26, 1109 (1993). Q

78. Nahar, S. N., Pradhan, A. K.: J. Phys. B 27, 429 (1994). Q

79. Nakajima, T., Chang, T. N.: Z. Phys. D 36, 41 (1996). Q

80. Nandi, T., Kurup, M. B., Prasad, K. G., Meenakshi Raja Rao, P., Padmanabhan, S., Krishnamurty, G., Mishra, A. P.: J. Quant. Spectrosc. Radiat. Transfer 49, 389 (1993). I,

81. Nitz, D. E., Bergeson, S. D., Lawler, J. E.: J. Opt. Soc. Am. B 12, 377 (1995). I.

82. Oates, C. W., Vogel, K. R., Hall, J. L.: Phys. Rev. Lett. 76, 2866 (1996). L

83. Olsen, J., Godefroid, M. R., Joensson, P., Mamqvist, P. A., Froese Fischer, C.: Phys. Rev. E 52, 4499 (1995). Q

84. Pinnington, E. H., Berends, R. W., Lumsden, M.: J. Phys. B 28, 2095 (1995). L

85. Pinnington, E. H., Ji, Q., Guo, B., Berends, R. W., van Hunen, J., Biemont, E.: Can. J. Phys. 71, 470 (1993). CP, L

86. Pinnington, E. H., van Hunen, J. J., Gosselin, R. N., Guo, B., Berends, R. W.: Phys. Scr. 49, 331 (1994). L

87. Pradhan, A. K., Berrington, K. A.: J. Phys. B 26, 157 (1993). Q

88. Quinet, P., Biemont, E.: Bull. Soc. R. Sci. Liege 62, 373 (1993). CA

89. Reinhardt, T., Maichel, J., Banmann, M., Krueger, J.: Z. Phys. D 34, 87 (1995). L

90. Rykova, O. V., Verolainen, Y. F.: Opt. Spectrosc. 76, 23 (1994). CP

91. Sabsabi, M., Cao, M., Gravelle, D. V., Vacquie, S.: J. Phys. D 27, 2388 (1994). E

92. Schmoranzer, H., Volz, U.: Phys. Scr. T47, 42 (1993). L

93. Scholl, T. J., Rosner, S. D., Holt, R. A.: Phys. Rev. A 53, 2130 (1996). L

94. Sperger, R., Schelm, B., Kock, M., Neger, T., Ulbel, M.: J. Quant. Spectrosc. Radiat. Transfer 51, 779 (1994). E

95. Szonert, J., Bieniak, B., Glodz, M., Piechota, M.: Z. Phys. D 33, 177 (1995). L

96. Tanner, C. E., Livingston, A. E., Rafac, R. J., Kukla, K. W., Berry, H. G., Kurtz, C. A.: Nucl. Instrum. Methods Phys. Res., Sect. B 99, 117 (1995). CM

97. Tayal, S. S.: J. Phys. B 28, 5193 (1995). Q

98. Tchang-Brillet, L. (Ed.) 1996. 5th International Colloquium on Atomic Spectra and Oscillator Strengths for Astrophysical and Laboratory Plasmas, Invited Papers. Meudon, France: Physica Scripta (in press).

99. Theodosiou, C. E., Curtis, L. J., Nicolaides, C. A.: Phys. Rev. A 52, 3677 (1995). Q

100. Tong, M., Froese Fischer, C, Sturesson, L.: J. Phys. B 27, 4819 (1994). Q

101. Traebert, E.: J. Phys. B 29, L217 (1996). L

102. Verner, D. A., Barthel, P. D., Tytler, D.: Astron. Astrophys. Suppl. Ser. 108, 287 (1994). CP

103. Volz, U., Majerus, M., Liebel, H., Schmitt, A., Schmoranzer, H.: Phys. Rev. Lett. 76, 2862 (1996). L

104. Volz, U., Marger, D., Roth, H., Schmoranzer, H.: J. Phys. B 28, 579 (1995). L

105. Weiss, A. W.: Phys. Rev. A 51, 1067 (1995). Q

106. Wiese, W. L., Fuhr, J. R., Deters, T. M. 1996. Atomic Transition Probabilities of Carbon, Nitrogen, and Oxygen - A Critical Data Compilation. J. Phys. Chem. Ref. Data, Monograph No. 7. CP

107. Yan, Z.-C., Drake, G. W. F.: Phys. Rev. A 52, R4316 (1995). Q

108. Ynnerman, A., Froese Fischer, C.: Z. Phys. D 34, 1 (1995). Q

109. Zerne, R., Caiyan, L., Zhankui, I., Larsson, J., Svanberg, S.: Z. Phys. D 32, 187 (1994). L 
TABLE 1. Important Literature References

\begin{tabular}{|c|c|c|}
\hline Al l: 72 & Cs l: 56,96 & $\begin{array}{l}\text { O I: } 106 \\
\text { O II: } 106 \\
\text { O III: } 46,106 \\
\text { O IV: } \mathbf{1 0 6} \\
\text { O V: } 41,44,106\end{array}$ \\
\hline $\begin{array}{l}\text { Ar I: } 49,61 \\
\text { Ar II: } 55,80,91 \\
\text { Ar III: } 80\end{array}$ & $\begin{array}{l}\text { Fe I: } 3,37,64 \\
\text { Fe II: } 4,8,26,36,59,75,78,87 \\
\text { Fe III: } 76 \\
\text { Fe VIII: } 69 \\
\text { Fe IX: } 69 \\
\text { Fe X: } 69,101\end{array}$ & $\begin{array}{l}\text { P I: } 13 \\
\text { P II: } 45\end{array}$ \\
\hline $\begin{array}{l}\text { В I: } 27,83 \\
\text { B II: } 41,50,105,108\end{array}$ & $\begin{array}{l}\text { Ga I: } 66 \\
\text { Ga II: } 43\end{array}$ & Rb I: 67,95 \\
\hline $\begin{array}{l}\text { Ba. I: } 71 \\
\text { Ba II: } 84\end{array}$ & He l: $28,29,49,65,88,104$ & $\begin{array}{l}\text { S I: } 14,40 \\
\text { S II: } 23,61 \\
\text { S III: } 53,77,97 \\
\text { S IV: } 72 \\
\text { S V: } 22\end{array}$ \\
\hline $\begin{array}{l}\text { Be I: } 105 \\
\text { Be IH: } 90\end{array}$ & $\mathrm{Hg}$ II: 70,90 & $\begin{array}{l}\text { Si: } 77 \\
\text { Si II: } 7,25,72\end{array}$ \\
\hline Hi I: 24 & K I: 67 & $\begin{array}{l}\text { Sr 1: } 71 \\
\text { Sr II: } 84\end{array}$ \\
\hline $\begin{array}{l}\text { C I: } 106 \\
\text { C II: } 10,39,106 \\
\text { C III: } 63,106\end{array}$ & $\begin{array}{l}\text { Kr I: } 49,74,92 \\
\text { Kr II: } 16\end{array}$ & Ti II: 15,64 \\
\hline $\begin{array}{l}\text { Ca I: } 17,19,35 \\
\text { Ca II: } 19,57,58\end{array}$ & Li I: $17,30,67,107$ & $\begin{array}{l}\text { T] II: } 20 \\
\text { T] III: } 20\end{array}$ \\
\hline $\begin{array}{l}\text { Cd II: } 86 \\
\text { Cd III: } 54\end{array}$ & $\begin{array}{l}\text { Mg I: } 22 \\
\text { Mg II: } 99 \\
\text { Mg JII: } 90\end{array}$ & $\begin{array}{l}\text { Xe I: } 2,74 \\
\text { Xe II: } 9,11,21 \\
\text { Xe III: } 11\end{array}$ \\
\hline $\begin{array}{l}\text { Cl I: } 12 \\
\text { Cl II: } 58\end{array}$ & $\begin{array}{l}\text { N I: } 100,106 \\
\text { N II: } 47,106 \\
\text { N III: } 5,10,38,106 \\
\text { N IV: } 42,106\end{array}$ & $\begin{array}{l}\text { Zn I: } 109 \\
\text { Zn II: } 6,90\end{array}$ \\
\hline $\begin{array}{l}\text { (o I: } 81 \\
\text { (o II: } 32\end{array}$ & $\begin{array}{l}\text { Na I: } 18,67,68,82,103 \\
\text { Na II: } 51 \\
\text { Na III: } 33\end{array}$ & \\
\hline $\begin{array}{l}\text { ('r [: } 89 \\
\text { (ir II: } 6,52,85,94\end{array}$ & $\begin{array}{l}\text { Ne I: } 49,62,79 \\
\text { Ne II: } 62 \\
\text { Ne III: } 33\end{array}$ & \\
\hline
\end{tabular}




\section{WORKING GROUP 3: COLLISION PROCESSES}

D. R. Schultz

Excitation and ionization of atoms and ions by electron-impact continues to be an area of very active investigation. Access to the most up-to-date data produced may be obtained either through new works which provide collections, evaluations, and recommendations, or through the original works which can be located through bibliographic databases and articles.

For example, a new collection of recommended cross sections for excitation and ionization of the ground and excited states of atomic hydrogen has been compiled by Janev and Smith [1] complementing earlier work which also included collisions with ground and excited hydrogen molecules, hydrogen molecular ions, helium, and helium ions [2]. Also, an extremely valuable and comprehensive work is contained in the proceedings and collected results of the atomic data assessment meeting hosted by the Rutherford Appleton Laboratory in 1992 [3]. This meeting was the latest in a series of meetings beginning in 1975 which have taken as their goal the elucidation of atomic data for astrophysical and laboratory plasmas. The present volume [3] provides collections of references, compilations of cross sections and rate coefficients, and some recommended values for these, for atoms and ions ranging $\mathrm{H}$ to $\mathrm{Fe}$.

Other reviews and collections of electron-impact data appearing during the period 1993-1996 include a compilation of data for important nebula emission lines by Pradhan and Peng [4] and a review of excitation of $\mathrm{C}, \mathrm{O}, \mathrm{Fe}$, and rare gas ions by Tayal $\mathrm{et}$ al. [5]. The latter is part of a compendilim [6] also containing reviews and recommendations of data for elastic scattering, ionization, and recombination in low temperature fusion plasmas.

Large scale projects and ongoing lines of data generation by key producers also continue to increase the knowledge base of electron-impact phenomena. In particular, the so-called Iron Project has sought to bring together a number of experts to provide fine-structure collision strengths and rate coefficients for Fe ions and other ions of heavy elements, along the lines of the previous Opacity Project. Data from the Opacity Project (TOPbase) is directly available through the widely used file transfer protocol (ftp). TOPbase is available at the Centre de Donnés de Strasbourg, France (at Internet Protocol (IP) address 130.79.128.5, with account name "tophase" and password "Seaton+") and NASA Goddard Space Flight Center (IP: 128.183.101.54, same account name and password). A brief description of the project, a list of important references, and instructions for downloading files may conveniently be found on the World Wide Web (at URL http://astro.u-strasbg.fr/OP.html). Work is underway to provide Web-based access to the Iron Project data (TIPbase, see URL http://ww .am.qub.ac.uk/projects/iron/). This Web site also lists the papers in the Iron Project series (we repeat this list here for the reader's convenience $[7,8,9,10,11,12,13,14,15,16,17,18,19,20,21,22,23,24,25,26])$. A hyperlink can also be followed to a database containing electronic versions of the published articles. Current publications may also be accessed on-line in the Astronomy and Astrophysics Supplement Series

(URL http://www ed-phys.fr/docinfos/Onlin@AetA.html).

Other recent published articles which represent continuations or extensions of work which seeks to compute electron-impact data for various iso-electronic or iso-nuclear sequences are represented by the relativistic distorted wave calculations of collision and oscillator strengths for $\Delta n=0$ transitions in $B$-like ions by Zhang and Sampson [27,28], cross sections and rate coefficients for excitation of $\Delta n=0$ transitions in Be-like ions with $6 \leq Z \leq 54$ by Safronova et $a l[29]$, and the collision strength and radiative decay rate calculations of Bhatia and Doschek for Fe X [30], Ne V [31], Mg VII [32], and Si IX [33]. These recent papers were all published in Atomir Data and Nuclear Data Tables. Consequently, an important resource for locating electrom-impact data is the cumulative index of this journal. This index along with the cumulative author index is distributed to subscribers and is now available on-line on the World Wide Web (URL http://www-cfadc.phy .ornl.gov/adndt/adndt.html). 
In fact, atomic data are becoming much more accessible with the advent of on-line resources. For example, much of the data on electron-impact ionization of ions measured at the Oak Ridge National Laboratory Multicharged Ion Research Facility over the last twenty years are now available through the World Wide Web (URL http://ww-cfadc.phy.ornl.gov/xbeam/xbmintro.html) in both graphical and tabular form. Other resources on the Web include access to bibliographic databases. The Oak Ridge National Laboratory Controlled Fusion Atomic Data Center (CFADC) maintains an on-line database of references to atomic collision data containing approximately 29,000 articles dating from 1978 to present which have been categorized by reaction (URL http://www-cfadc.phy.ornl.gov/search.html). A completely independent bibliography searchable by reaction category is provided by the Laboratoire de Physique des Gaz et des Plasmas at the Universite Paris-Sud, Orsay, France (URL http://gaphyor.lpgp.u-psud.fr/). Annotated bibliographies are also available such as that for electron collisions with positive ions by Itikawa [34] and the International Bulletin on Atomic and Molecular Data for Fusion available from the International Atomic Energy Agency [35]. The content of the Bulletin, however, is largely composed from the updated files of the CFADC on-line bibliography, and therefore, the newly available World Wide Web sites will provide generally the most up-to-date and easily accessible source of bibliographic information.

It should be noted that significant progress has been made both theoretically and experimentally over the past three years in advancing the techniques of studying electron-impact phenomena. For instance, the use of ion-storage rings, which utilize electron-coolers, as platforms for electron-ion reactions, promises to provide new levels of detail in recombination, excitation, and ionization cross sections (see e.g. Kenntuer ct al. [36]). From a theoretical point of view, new techniques are being developed that have similarly advanced the statc-of-the-art for few-electron systems such as the convergent close coupling method of Bray and Stelbovics [37], the hyperspherical close-coupling approach of Kato and Watanabe [38], the Rmatrix with pseudo-states method of Bartschat et al. [39], the direct solutiou of the Schrödinger equation on a numerical lattice [40], and the extension of perturbation theory approaches through inclusion of improved approximations to the final state wavefunction $[41,42]$.

Finally, it is worth noting some statistics regarding the number of works published between 1993 and 1996 regarding olectron-impact excitation and ionization. Using the CFADC on-line database, it is found that many works concentrate on the fundamental one and two-electron targets H and He (about 60 references regarding ionization in collisions of electrons with $\mathrm{H}, \mathrm{He}^{+}$, and $\mathrm{He}$, and about 75 regarding excitation in these systems). In contrast, only about 25 references were found to ionization of all ions of $\mathrm{Li}, \mathrm{Be}, \mathrm{B}, \mathrm{C}$, $\mathrm{N}$, and $\mathrm{O}$, (about 30 regarding excitation). Interest is also focused on certain challenging and key species such as iron ions ( 15 references for ionization, about 40 for excitation). Clearly, the continued study of electron-impact of atoms and ions will further the refinement of cross sections, rates, and strengths for systems already studied, and provide new information for those which remain unexplored.

The author gratefully acknowledges helpful suggestions regarding this review made by M.S. Pindzola, D.II. Madison, K. Bartschat, and H.L. Zhang.

\section{References}

[1] Janev, R.K. and J.J. Smith, "Cross sections for collision processes of hydrogen atoms with electrons, protons, and multiply charged ions," Atomic and Plasma-Material Interaction Data for Fusion (Supplement to the journal Nuclear Fusion), 4 (1993).

[2] Janev, R.K., W.D. Langer, K. Hvans, and D.E. Post, Flementary processes in hydrogen-helium plasmas: Cross scotions and mate coefficiente, Spritger-Verlag, Berlin (1987).

[3] "Electron excitation data for analysis of spectral line radiation from intrared to $X$-ray wavelengths: Reviews and recommendations," J. Lang, editor, Atomic Data and Nuclear J)ata Tables 57, Nos. 1-2 (1994).

[4] Pradhan, A.K. and I.F. Peng, "Atomic data for the analysis of emission lines," in Space tolescope scicnoe institute symposium serics: The analysis of emission lines, R.E. Williams and M. Livio. editors, Cambridge Uaiversity Press. Cambridge: (1995). 
[5] Tayal, S.S., A.K. Pradhan, and M.S. Pindzola, "Excitation of atomic ions by electron impact," in Atomic and molecular processes in magnetic fusion edge plasmas, R.K. Janev, editor, Plenum, New York (1995), page 119.

[6] Atomic and molecular processes in magnetic fusion edge plasmas, R.K. Janev, editor, Plenum, New York (1995).

[7] Hummer, D.G., K.A. Berrington, W. Eissner, A.K. Pradhan, H.E. Saraph, and J.A. Tully, "Goals and Methods," Astronomy \& Astrophysics 279, 298 (1993) (paper I).

[8] Lennon, D.J. and V.M. Burke, "Effective collision strengths for infrared transitions in carbon-like ions," Astronomy \& Astrophysics Supplement Series 103, 273 (1994) (paper II).

[9] Zhang. II.L., M. Graziani, A.K. Pradhan, "Rate coefficients for electron-impact excitation of boron-like ions - Ne-VI, Mg-VIII, Al-IX, Si-X, S-XII, Ar-XIV, Ca-XVI and Fe-XXII," Astronomy \& Astrophysics 283, 319 (1994) (paper III).

[10] Saraph, H.F. and J.A. Tully, "Electron-excitation of the ${ }^{2} \mathrm{P}_{3 / 2}^{o}-{ }^{2} \mathrm{P}_{1 / 2}^{o}$ fine-structure transition in fluorine-like inns," Astronomy \& Astrophysics Supplement Series 107, 29 (1994) (paper IV).

[11] Butler, K. and C.J. Zeippen, "Effective collision strengths for transitions in the ground configuration of oxygen-like ions," Astronomy \& Astrophysics Supplement Series 108, 1 (1994) (paper V).

[12] Zhang, H.L. and A.K. Pradhan, "Collision strengths and rate coefficients for Fe-II," Astronomy \& Astrophysics 293, 953 (1995) (paper VI).

[13] Nahar, S.N., "Radiative dipole transition-probabilities for Fe-II," Astronomy \& Astrophysics 293, 967 (1995) (paper VII).

[14] Berrington, K.A., "Electron-excitation of the 3d ${ }^{4}$ 5D, ground-state, fine-structure transitions in Ti-like jons V-II, Cr-III, Mn-IV, Fe-V, Co-VI and Ni-VII," Astronomy \& Astrophysics Supplement Series 109, 193 (1995) (paper VIII).

[15] Pelan, J. and K.A. Berrington, "Electron-excitation of the ${ }^{2} \mathrm{P}_{3 / 2}^{o}{ }^{2} \mathrm{P}_{1 / 2}^{o}$ fine-structure transition in chlorine-like ions $\mathrm{Ar}$ II to Ni XII," Astronomy \& Astrophysics Supplement Series 110, 209 (1995) (paper IX).

[16] Galavis, M.E., C. Mendoza, and C.J. Zeippen, "Effective collision strengths for infrared transitions in silicon-like and sulfur-like ions," Astronomy \&. Astrophysics Supplement Series 111, 347 (1995) (paper X).

[17] Saraph, H.E. and P.J. Storey, "The $\mathrm{P}_{1 / 2}^{o}-\mathrm{P}_{3 / 2}^{o}$ fine-structure lines of Ar-VI, K-VII and Ca-VIII," Astronomy \& Astrophysics Supplement Series 115, 151 (1996) (paper XI).

[18] Berrington, K.A. and J. Pelan, "Electron-excitation of forbidden transitions in V-like ions Mn-III, Fe-IV, Co-V and Ni-VI," Astronomy \& Astrophysics Supplement. Series 114, 367 (1995) (paper XII).

[19] Bautista, M.A. and A.K. Pradhan, "Electron-excitation rates and emissivity ratios for forbidden transitions in N-III and Fe-II," Astronomy \& Astrophysics Supplement Series 115, 551 (1996) (paper XIII).

[20] Storey, P.J., H.E. Mason, and H.E. Saraph, "Electron-impact excitation of the Fe-XIV fine-structure transition ${ }^{2} \mathrm{P}_{1 / 2}^{o}$ ${ }^{2} \mathrm{P}_{3 / 2}^{\circ}, "$ Astronomy \& Astrophysics 309, 677 (1996) (paper XIV).

[21] Kisielius, R., K.A. Berrington, P.H. Norrington, "Electron-excitation of the fine-structure transitions in Hydrogen-like ions He-II and Fe-XXVI," Astronomy \& Astrophysics Supplement Series 118, 157 (1996) (paper XV).

[22] Nahar, S.N. and A.K. Pradhan, "Radiative transition probabilities for dipole allowed and forbidden transitions in Fe III," Astronomy \& Astrophysics Supplement Series (in press) (paper XVII).

[23] Zhang. H.L., "Electron impact excitation collision strengths and rate coefficients for Fe III." Astronomy \& Astrophysics Supplement Series (submitted) (paper XVIII).

[24] Quinet, P., M. LeDourneuf, and C.J. Zeippen, "Radiative transition probabilities for forbidden lines in Fe IJ," Astronomy \& Astrophysics Supplement Series (submitted) (paper XIX).

[25] Bautista, M.A., "Photoionization cross sections and oscillator strengths for Fe I," Astronomy \& Astrophysics Supplement Series (submitted) (paper XX).

[26] Pelan, J. and K.A Berrington, "Electron excitation of fine-structure transitions involving the $3 \mathrm{~d}^{6} 4 \mathrm{~s}^{2}{ }^{5} \mathrm{I}$ ) ground state and the $3 \mathrm{~d}^{7} 4 \mathrm{~s}{ }^{5} \mathrm{~F}$ metastable state of Fe I", Astronomy \& Astrophysirs Supplement Series (submitted) (paper XXI)

[27] Zhang, H.L. and D.H. Sampson, "Relativistic distorted wave collision strengths and oscillator strengths for the 105 $\Delta n=0$ transitions with $n=2$ in the 85 B-like ions with $8 \leq Z \leq 92$," Atomic Data and Nuclear Data Tables 56, 41 (1994).

[28] Zhang, H.L. and D.H. Sampson, "Relativistic distorted wave collision strengths and oscillator strengths for all possible $n=2-n=3$ transitions in B-like ions," Atomic Data and Nuclear Data Tables 58, 255 (1994).

[29] Safronova, U.I., A.S. Shlyaptseva, T. Kato, K. Masai, and L.A. Vainshtein, "Cross sections and rate coefficients for excitation of $\Delta n=0$ transitions in Be-like ions with $6 \leq Z \leq 54$," Atomic Daia and Nuclear Data Tables 60, 1 (1995).

[30] Bhatia, A.K. and G.A. Doschek, "Atomic data and spectral line intensities for Fe X," Atomic Data and Nuclear Data Tables 60, $145(1995)$

[31] Bhatia, A.K. and G.A. Doschek, "Atomic data and spectral line intensities for C-like Ne V," Atomic Data and Nuclear Data Tables 55, 215 (1993).

[32] Bhatia, A.K. and G.A. Doschek, "Atomic data and spectral line intensities for C-like Mg VII," Atomic Data and Nuclear Data Tables 60, $145(1995)$.

[33] Bhatia, A.K. and G.A. Doschek, "Atomir data and spectral line intensities for C-like Si IX," Atomic Data and Nuclear Data Tables 55, 281 (1993).

[34] ltikawa, Y., "Annotated bibliography on electron collisions with atomic positive ious: Excitation and ionization, $1990-$ 1994," Atomic Data and Nuclear Data Tables 63, 315 (1996).

[35] Write to: Atomic and Molecular Data Unit, Nuclear Data Section, International Atomic Fnergy Agency, Wagranerstrasse 5, P.O. Box 100, A-1400 Vienna, Austria (email: psin@ripcrs01.iaea.or.at).

[36] Kenutner, J., .l. linkmann, N.R. Badnell, (: Broude, D). Habs, (x. Hofmann, A. Muller, M.S. Pindzola, S. Salzborn, I). Schwalm, and A. Wolf, "Resonant electron impart ionization and recombination of li-like ( $\mathrm{l}^{14+}$ and $\mathrm{Si}^{11+}$ at the Heidelberg 'Test Storage Ring," Nucl. Instrum. Methods Phys. Res. B 98142 (1995). 
[37] Bray, I. and A.T. Stelbovics, "Calculation of the total ionization cross section and spin asymmetry in electron-hydrogen scattering," Phys. Rev. Lett. 70, 746 (1993).

[38] Kato, D, and S. Watanabe, "Two-electron correlations in $e+H \rightarrow e+\epsilon+p$ near threshold," Phys. Rev. Lett. 74, 2443 (1995).

[39] Bartschat, K., E.T. Hudson, M.P. Scott, P.G. Burke, and V.M. Burke, "Electron scattering by complex atoms and ions at intermediate energies," J. Phys. B 29, 115 (1996).

[40] Pindzola, M.S. and D.R. Schultz, "Time-dependent close-coupling method for electron-impact ionization of hydrogen," Phys. Rev. A 53, 1525 (1996).

[41] Alt, E.O. and A.M. Mukhamedzhanov, "Asymptotic solution of the Schrödinger equation for three charged particles," Phys. Hev. A 47, 2004 (1993).

[42] Jones, S., D.H. Madison, A. Franz, and P.L. Altick, "Three-body distorted-wave Born approximation for electron-atom ionization," Phys. Rev. A 48, R22 (1993). 


\section{CHEMICAL REACTIONS}

The following table of measurements of reaction rates at low temperatures was provided to W. H. Parkinson by Ewine F. van Dishoeck.

TABLF, 2. Neutral Reactions Studied at $\mathrm{T} \leq 295 \mathrm{~K}$ in Birmingham/Rennes

\begin{tabular}{|c|c|c|c|}
\hline Reaction & T range & 'Туре & Reference \\
\hline $\mathrm{CN}+\mathrm{O}_{2}$ & $99-761 \mathrm{~K}$ & cell & Sims \& Smith 1988, Chem. Phys. Lett. 151, 481. \\
\hline $\mathrm{CN}+\mathrm{NO}+\mathrm{M}$ & $99-450 \mathrm{~K}$ & $\mathrm{cell}$ & Sims \& Smith 1993, J. Chem. Soc. Faraday Trans. 89, 1. \\
\hline $\mathrm{OII}+\mathrm{IICl}, \mathrm{C}_{2} \mathrm{H}_{6}$ & $138-298 \mathrm{~K}$ & cell & Sharkey \& Smith 1993, J. Chem. Soc. Faraday Trans. 89, 631. \\
\hline $\mathrm{OH}+\mathrm{CH}_{4}$ & $178-298 \mathrm{~K}$ & & \\
\hline $\mathrm{OH}+\mathrm{CO}$ & $80-298 \mathrm{~K}$ & cell & Frost et al. 1993, J. Phys. Chem. 97, 12,254. \\
\hline $\mathrm{CN}+\mathrm{O}_{2}$ & $13-295 \mathrm{~K}$ & CRFSU & Sims et al. 1994, J. (Whem. Phys. 100, 4,229. \\
\hline $\mathrm{CN}+\mathrm{NH}_{3}$ & $25-295 \mathrm{~K}$ & & \\
\hline $\mathrm{CN}+\mathrm{C}_{2} \mathrm{H}_{2}, \mathrm{C}_{2} \mathrm{H}_{4}, \mathrm{C}_{2} \mathrm{H}_{6}$ & $25-298 \mathrm{~K}$ & combined & Sims et al. 1993, Chem. Phys. Lett. 211, 461. \\
\hline $\mathrm{CN}+\mathrm{CH}_{4}, \mathrm{C}_{3} \mathrm{H}_{6}$ & $160-298 \mathrm{~K}$ & & \\
\hline $\mathrm{OH}+\mathrm{N}$ & $\mathrm{J} 03-294 \mathrm{~K}$ & aell & Smith \& Stewart 1994, J. Chen. Soc. Faraday Trans. 90, $3,221$. \\
\hline $\mathrm{OH}+\mathrm{O}$ & $158-294 \mathrm{~K}$ & & \\
\hline $\begin{array}{l}\mathrm{OH}+\text { but-l-cne, } \\
(\mathrm{E}-\& . \mathrm{Z} \text {-) but-2-ene }\end{array}$ & $23-245 \mathrm{~K}$ & CRESU & Sims et al 1994, J. Chem. Soc. Faraday Trans. 90, 1,473. \\
\hline $\mathrm{OH}+\mathrm{HBr}$ & $23-295 \mathrm{~K}$ & $\begin{array}{l}\text { CREsit }+ \\
\text { throretical }\end{array}$ & Sims et al 1994, J. Chem. Phys. 101, 1,748. \\
\hline $\mathrm{OH}+\mathrm{NO}+\mathrm{M}$ & $23-301 \mathrm{~K}$ & combined & Sharkey et al. 1994, J. Chem. Sor. Faraday Trans. 90, 3,609. \\
\hline $\begin{array}{l}\mathrm{NO}\left(\mathrm{X}^{2} 11\right) \text { rovibrul } \\
\text { energy transfer }\end{array}$ & $80-295 \mathrm{~K}$ & cell & $\begin{array}{l}\text { Islam at al. 1994, J. Phys (hem. 98, 9,285. } \\
\text { Islam th al. 1995, J. Chem. Phys. 103, 9,676. }\end{array}$ \\
\hline $\mathrm{CH}+\mathrm{O}_{2}, \mathrm{NO}$ & $13-708 \mathrm{~K}$ & combined & Bocherel ef al. 1996, f. Phys, (Them, 100, 3,063. \\
\hline$\left(\mathrm{H}+\mathrm{NH}_{3}\right.$ & $23-29.5 \mathrm{~K}$ & ('RESU & \\
\hline $\mathrm{CH}+\mathrm{N}$ & $216-584 \mathrm{~K}$ & cell & Brownsword et al. 1996, J. Chem. Soc. Faraday 'Trans. 92, 723. \\
\hline$\left(\mathrm{H}(\mathrm{v}=1)+\mathrm{CO}, \mathrm{N}_{2}\right.$ & $23-584 \mathrm{k}$ & combined & Herbert et al., I. Phys Cheto., submitted. \\
\hline $\begin{array}{l}\mathrm{CH}+\mathrm{CH}_{4}, \mathrm{C}_{2} \mathrm{H}_{2}, \mathrm{C}_{2} \mathrm{H}_{4} \\
\left(\mathrm{CH}_{6} \text { and hut-l-che }\right.\end{array}$ & $23-295 \mathrm{~K}$ & (:RESCT & Canosa of al, A \& A, submitted. \\
\hline $\begin{array}{l}\text { (:Il }+\mathrm{H}_{2} \rightarrow \mathrm{r}: \mathrm{ll}_{:} \\
\text {by racliative amon. }\end{array}$ & & theorctical & Browusword et al., $A_{\mathrm{p}} \mathrm{J}$, in preparation. \\
\hline$O \|(y=0,1)+I_{2} \cdot \Pi_{2}$ & 13.7116 & combint & Browuswort al al., 1. Chem. Phyo., in preparation. \\
\hline
\end{tabular}




\section{WORKING GROUP 4: LINE BROADENING}

\section{N. Feautrier, Chair}

The field of line broadening has continued to be very active during the last three years, as could be observed during both the 12th International Conference on Spectral Line Shapes (ICSLS, Toronto 1994) (1) and the 13th ICSLS (Firenze 1996) (2). This activity has been mostly stimulated by the interpretation of recent observations or by the preparation of space investigations.

During the last period, most of the works were concentrated on applications of methods established in the preceding years, yielding many results, so new data bases were elaborated and existing ones improved. It is not the aim of this report to be exhaustive; we will simply give a selection of references on the basis of their astrophysical interest.

\section{Stark Broadening}

\section{Stark Broadening for Plasmas of Low Densitites: The Impact limit}

For diffuse to moderately dense plasmas, the Opacity P'roject includes extensive calculations of atomic data required for opacity determination, particularly Stark broadening constants for atomic and ionic lines involving relatively low excited states. These data are very precise, and approximate formula are available for transitions involving higher excited states.

Approximative methods ( $\overline{\mathrm{g}}$ method, semiclassical perturbative theory) have been used extensively to provide broadening parameters with a mean accuracy better than 30 percent for a large number of lines. Some results are only available in electronic form via an anonymous ftp to the CDS center (see the Editorial in A\&AS, Vol. 103, No1). Furthermore, much work of high quality has been done experimentally.

Table 3 presents results for many transitions; the numbers refer to the reference list.

TABLE 3. Important Literature References

\begin{tabular}{llll}
\hline Al I, JI], XI & $3,4,5$ & Na I, IV & 20,21 \\
Ar II & 6,7 & Ne VII, VIII & 22,21 \\
AsII & 8 & Ni I, II & 23,24 \\
B I & 9 & N V & 13 \\
Be I & 10 & O IV, V, VI & $25,26,13$ \\
Bi II & 11 & Pa I & 27 \\
Br II & 8 & S III, IV & 28 \\
C II, IV & 12,13 & Sb II, III & 6 \\
Ca II & 14 & Si XII & 5 \\
Cd II & 15 & V I & 29 \\
Fe II, VII & $16,17,18$ & Zn II & 15 \\
Mg I & 19 & & \\
\hline
\end{tabular}

Results for isoelectronic sequences, such as B-sequence (9), or series four and five times charged ion lines (30) are of particular interest. Because of the speed with which such calculations can be made, it would be interesting that more systematic work be done and presented as a data base. $A$ complementary direction concerns investigations of systematic trends of Stark broadening parameters. Regularities of these parameters have been investigated (31). Finally, one should mention an important work on the Stark broadening theory of solar Rydberg lines $(32,33)$ and an interesting study of the profile of the $\mathrm{P} \alpha$ line of II from the line center to the far wings under the physical conditions of stellar atmospheres (34). 
Beyond the Quasistatic Limit gor Ionic Perturbers: Hot and Dense Plasmas andor HyDROGENIC: EMITTER

In the case of dense and hot plasmas, interactions with ionic perturbers become a major source of broadening. Due to the linear Stark effect, it is the same situation whether the emitter is an $\mathrm{H}$ atom or an hydrogenic ion. The quasistatic approximation used for ionic broadening at low densities is no longer valid and simultancous strong interactions between the radiator and the surrounding perturbers must. be taken into account. Much effort has been devoted to this many body dynamical problem both on the methods and the applications. Important results have been obtained theoretically or experimentally for lines of $\mathrm{H}(35-37), \mathrm{He}^{+}(36,38,39), \mathrm{N} V(40)$ and multicharged hydrogenic ions (41). Extensive tables (42) and parametrized formulae (43) are available. Analytic expressions have been obtained for the lines of one electron ions (44), and wing formulae for plasma broadened spectral lines of hydrogenic ions (45). Ion dynamics effects are also studied in He lines (46-49).

Far wings of the Lyman $\alpha$ line of II have been studied in a quasi molecular approach in the physical conditions of white dwarfs (50).

\section{Line Broadening by Foreign Gases and Molecular Line Broadening}

\section{BroAdening of ATOMIC LINES}

Calculations involving various degrees of sophistication in the determination of interatomic interactions have been pulslished: self broadening of He triplet lines (51), and $\mathrm{Sr}$ resonance line perturbed by HI (52). One has to mention interesting results on the collisional broadening of $\mathrm{Mg}$ Rydberg lines (53) and of $\mathrm{s}-\mathrm{p}$ and p-s atomic transitions of $\mathrm{Na}, \mathrm{Ca}$, and Fe (54) perturbed by $\mathrm{H}$ atoms.

\section{MOLECU H,AR BROADENING;}

Many important results have been obtained, mainly in the infrared spectra. For astrophysical applications we will quote particularly the calculation of the broadening parameters of $\mathrm{CO}$ perturbed by He (55), and the self-broadening of $\mathrm{N}_{2}(56)$. Many theoretical or experimental investigations in this domain have been stimulated by new spatial observations of planenary atmospheres or by the need of new molecular data in particular for Jupiter and Titan atmospheres. Particular attention has been paid to collisional broadening in various bands of $\mathrm{CO}_{2}(5.5,57), \mathrm{NH}_{3}(58-60), \mathrm{CH}_{4}(61-68), \mathrm{C}_{2} \mathrm{H}_{2}(69), \mathrm{C}_{2} \mathrm{H}_{4}(70), \mathrm{H}_{2} \mathrm{O}(71) . \Lambda$ special attention has been paid to the problem of line mixing in $\mathrm{CO}(55),(\mathrm{CO})_{2}(55),\left(\mathrm{C}_{2} \mathrm{H}_{2}(69)\right.$. 'This considerable effort in molecular line broadening has contributed to improve molecular databases.

\section{Colbision InduCED SPECTRA}

Collision induced spectra contribute to a major part of the opacity in the outer planets, which are composed of non-polar species like $\mathrm{H}_{2}$. and He. Recently a new interest for collision induced spectra las appeared with the need of opacities for the modelling of cool and dense stars: white dwarfs, brown dwarfs, et.r.

Accurate calculations of $\mathrm{H}_{2}-\mathrm{H}_{2}(72)$, $\mathrm{H}_{2}-\mathrm{He}(73), \mathrm{CO}_{2}-\mathrm{CO}_{2}(74), \mathrm{N}_{2}-\mathrm{N}_{2}(75)$, and $\left(\mathrm{H}_{4}-\mathrm{H}_{2}(69)\right.$ pairs have been carried ont. The acruracy of the results depends directly on the quality of the intermoleculat potentials. 


\section{I)ATA BASES}

A number of interesting papers have been published in the special issue of JQSRT (52, 1994) devoted to atmospheric spectroscopy applications. One has to mention in particular the Smithsonian Astrophysical Observatory Database which combines the best currently available line parameters (76), a PC/AT new version of (ieisa l)ata bank (77), and the TDS spectroscopic databank for spherical tops like $\mathrm{CH}_{4}, \mathrm{CF}_{4}$, atc. $(78)$.

\section{References}

1. A I P Conference Proceding 328 (1995).

2. 13th ICSLS Abstracts, Firenze, June 16-21 (1996).

3. Dimitrijevic, M. S. \& Sahal-Brchot, S., Physica Scripta 49, 34 (1994).

4. Dimitrijevic, M. S.\& Sahal-Brchot, S., Astron. Astrophys. Suppl. Ser, 99, 585 (1993).

5. Dimitrijevic, M. S. \& Sahal-Brchot, S., Astron. Astrophys. Suppl. Ser. 105, 245 (1994).

6. Djenize, S., Skuljan, Lj. \& Konjevic, R., JQSRT 54, 581 (1995).

7. Dzierzega, K. \& Musiol, K., JQSRT 52, 747 (1994).

8. Popovic, L. G. \& Dimitrijevic, M. S., Physica Scripta 53, 325 (1996).

9. Glenzer, S., Hey, J. D. \& Kunze, H.-J., J. Phys. B, At. Mol. Opt. Phys. 27, 413 (1994).

10. Dimitrijevic, M. S. \& Sahal-Brchot, S., Astron. Astrophys. Suppl. Ser. 105, 243 (1994).

11. Dimitrijevic, M. S. \& Popovic, 1. C., Astron. Astrophys. Suppl. Ser, 101, 587 (1993).

12. Sarandacv, E. V. \& Salakhov, M. Kh., JQSR'T 54, 827 (1995).

13. Glenzer, S., Wrubel, T., Busher, S. \& Kunze, H.-J., J. Phys. B, At. Mol. Opt. Phys. 27, 5507 (1994).

14. Dimitrijevic, M. S. \& Sahal-Brshot, S., JQSRT 49, 157 (1993).

15. Popovic, L. \&., Vince, I., Dimitrijevic, M. S., Astron. Astrophys. Suppl. Ser. 102, 17 (1993).

16. Puric, J., Djenize, S., Sreckovic, A., Bukvic, S., Pivalica, S. \& Labat .J., Astron. Astrophys. Suppl. Ser. 102, 607 (1993).

17. Dimitrijevic, M. S., Astron. Astrophys. Suppl. Ser. 111, 565 (1995).

18. Dimitrijevic, M. S. \& Sahal-Brchot, S., Astron. Astrophys. Suppl. Ser. 101, 587 (1993).

19. Dimitrijevic, M. S. \& Sahal-Brchot, S., Physica Scripta 52, 41 (1996).

20. Sreckovic, A., Djenize, S. \& Bnkvic, S., Physica Scripta 53, 54 (1996).

21. Diunitrijevic, M. S. \&. Sahal-Brchot, S., Astron. Astrophys. Suppl. Ser. 107, 349 (1994).

22. Wrubel, Th., Glenzer, S., Büsher, S., Kunze, H.-J, \& Alexiou, S., Astron. Astrophys. 306, 1023 (1996).

23. Jjenize, S., Skuljan, L., Laba.t, J., Bukvic, S. \& Konjevic R., Astron. Astrophys. Suppl. Ser. 105, 115 (1994).

24. Dinitrijevic, M. S., Astron. Astrophys. Suppl. Ser. 114, 171 (1995).

25. Dimitrijevic, M. S. \& Sahal-Brchol, S., Astron. Astrophys. Suppl. Ser. 109, 551 (1995).

26. Blagojevic, B., Popovic, M. V., Konjevic, N. \& Dimitrijevic, M. S., Phys. Rev. E 50, 2986 (1994).

27. Dinitrijevic, M. S., Astron. Astrophys. Suppl. Ser. 100, 593 (1993).

28. Dimitrijevic, M. S., Djenize, S., Sreckovic, A. \& Platisa, M., Physica Scripta 53, 545 (1996).

29. Dimitrijevic, M. S. \& Sahal-Brchot, S., Astron. Astrophys. Suppl. Ser. 100, 91 (1993).

30. Dimitrijevic, M. S. \& Sahal-Brchot, S., Astron. Astrophys. Suppl. Ser. 100, 327 (1993).

31. Puric, J. \& Cuk, M., AIP Conference Proceeding 328, 79 (1995).

32. Van Regemorter, H. \& Hoang-Binh, D., Astron. Astrophys. 277, 623 (1993).

33. Hoang Binh, D., Astron. Astrophys. 286, 607 (1994).

34. Motapon, O., Picart, J. \& 'Tran Minh, N., J. Phys. B, At. Mol. Opt. Phys. 27, L91 (1994).

35. Stehlé. C. \& Jacquemot, S., Astron. Astrophys. 271, 348 (1993).

36. Schöning, 'T', Astron. Astrophys. 282, 994 (1994).

37. Könies, $A$ \& \& Günter, S., JQSRT 52,825 (1994).

38. Stehlé, $C_{\text {. }}$ Astron. Astrophys. 282, 699 (1994).

39. Stefanovic, I., Ivkovic, M. \& Konjevic N., Physica Scripta 52, 178 (1996).

40. Schöning, 'I', Astron. Astrophys. Suppl. Ser. 113, 579 (1994).

41. (illes D)., Stehlé, C., I. Phys. II (France) 5, 75 (1995).

42. Stehlé, C.., Astron. Astrophys. Suppl. Ser. 104, 509 (1994).

43. Clausset, F., Stehlé, C. \& Artru, M.-C. Astron. Astrophys. 287, 666 (1994),

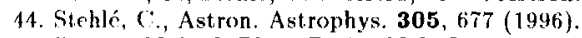

45. Scaton, M.I., J. Plys. B, At. Mol. Opt. Phys. 28, 565 (1995).

16. Schöning, T., J. Physs. B, At. Mol. Opt. Phys. 27, 4501 (1994).

47. Pere\%, C., Aparico, I. A., de la Rosa, I., Mar, S. \& Gigosos M. A., Phys. Rev. E 51, 3764 (1995).

48. Mijatovic, Z., Konjevic, N., Ivkovic, M. \& Kobilarov, R., Phys. Rev. E 51, 4891 (1995).

49. Büscher, S., (Henzer, S., Wrubel, Th. \& Kunze, H.-J., JQSRT 54, 73 (1994).

51). Allard, N. F., Koester, D., Feautrier, N. \& Spielfiedel, A., Astron. Astrophys. Suppl. Ser. 108, 417 (1994).

51. Leo, P.J., Peach, G.\&. Whittingham, J. Plys. B, At. Mol. Opt. Phys. 28, 591 (1995).

52. Faurobert-Scholl, M., Feautrier, N., Machefert, F., Petroway, K. \& Spiejfiedel A., Astron. Astrophys. Suppl. Ser. 298, $289(1995)$.

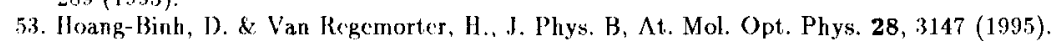


54. Anstee, S.D. \& O'Mara, B.J., Mon. Not. R. Astron. Soc. 276, 859 (1995).

55. Filippov, N. N. \& Tonkov, M. V., JQSRT 50, 111 (1993).

56. Boissoles, J., Tipping, R. H. \& Boulet, C., JQSRT 51, 679 (1994).

57. Boissoles, J., Le Doucen, R., Thibault, F. \& Boulet C., JQSRT 52, 361 (1994).

58. Varanasi, P. \& Gopala, A., JQSRT 49, 383 (1993).

59. Pine, A. S., Markov, V. N., Buffa, G. \&. Tarrimi, O., JQSRT 50, 337 (1993).

60. Baldacchini, G., Buffa, G., Ciucri, A., d'Anato, F. \& Tarrini, O., JQSRT 53, 671 (1994).

61. Singh, K. \& O'Brien, J.J., JQSRT 52, 75 (1994).

62. Margolis, J.S., JQSRT 49, 71 (1993).

63. Vujkovic, Cvijin P., Wells, W.K., Mendas, I., Delaney, J.K., I.umine, J.J., Hunter, D.M. \& Atkinson, C.H., JQSRT 49, 639 (1993).

64. Benner, D.C., Devi, V.M., Smith, M.A.H. \& Rinslanbd, C.P., JQSRT 50, 65 (1993).

65. Strong, K., Taylor,. F.W., Calcutt, S.B., Remedios, J.J. \& Ballad J., JQSRT 50, 563 (1993).

66. Margolis, J. S., JQSRT 50, 431 (1993).

67. Gabaud, T. \& Champion, J. P., JQSRT 52, 303 (1994).

68. Kadak, B.B., Lumine, J.I., Hunter, D.M. \& Atkinson, G.H., JQSRT 52, 809 (1994).

69. Pine, A.S., JQSRT 50, 149 (1993).

70. Reuter, D.C. \& Sirota, J.M., JQSRT 50, 477 (1993).

71. Gamache, R.R., Hartmann, J.-H. \& Rosenmann, J., JQSRT 52, 431 (1994).

72. Schaefer, J., Astron. Astrophys. 284, 1015 (1994).

73. Brodbeck, C., Nguyen-Van, Thanh \& Bouanich, J.-P., Phys. Rev. A 51, 1209 (1995).

74. Vigasin, A.A., 'Tarakanova, E.G. \& Tchlenova, G.V., JQSRT 50, 695 (1993).

75. Margolis, J.S., JQSRT 49, 71 (1993).

76. Chance, K., Jucks, K.W., Johnson, D.G. \& Traub, W.A., JQSRT 52, 447 (1994)

77. Husson, N., Bonnet, B., Chédin, A., Scoti, N.A., Chursin, A.A., Golovko, V.F. \& Tyuterev, VI.G., JQSRT 52, 425 (1994).

78. Tyuterev, V.L., Babikov, Yu.L., Tashkun, S.A., Perevalov, V.I., Nikitin, A., Champion, J.P., Wenger, Ch., Pierre, C., Pierre, G., Hilico, J.C. \& Loete, M., JQSRT 52, 459 (1995).

\section{WORKING GROUP 5: MOLECULAR STRUCTURE AND TRANSITION DATA}

E. F. van Dishoeck, Chair

The most significant development in the last three years has been the enormous expansion and availability of atomic and molecular databases in electronic form (CD-ROM, ft.p, World-Wide-Web). ${ }^{1-5}$ Millions of molecular lines ranging from the millimeter to the extreme ultraviolet part of the spectrum can now be accessed on-line, and improved software allows rapid searches through the data bases. At the same time, the astrophysical needs for such large data bases have increased considerably. Spectral line surveys at submillimeter wavelengths typically contain thousands of rotational lines, ${ }^{6}$ high resolution infrared spectra from the ground and the Infrared Space Obscrvatory require large amounts of information on the vibrational transitions, ${ }^{7,8}$ whereas large format CCDs in the optical and ultraviolet allow large wavelength ranges to be scanned for electronic transitions. The ast rophysical modeling has improved to the stage that highly accurate molecular data are essential. A well-known example, which has been studied intensively by several groups over the last decade, is provided by the VUV electronic transitions of $\left(0 .{ }^{21.31}\right.$ For models of cool stars and brown dwarfs, information on the weaker transitions, whose intensities are five orders of magnitude less than those of the strongest transitions, proves to be essential. ${ }^{9}$

There have been significant developments in the experimental techniques and theoretical methods for determining molecular structure, both of stable species, and of radicals and ions. Of particular interest is the progress in measuring and calculating the spectra of large molecules, including PAI's, long carbou chains and $\mathrm{C}_{60}$.

The following summary is based on contributions sent to me by U.(i. Jørgenson, T. Oka, J.P. Phillips, F. Rostas, P.L. Smith, and P. Thaddeus in the summer of 1996. Other topics have been added through a literature search. This report focuses on the highlights, and concerns only inolecules of astrophysical interest. No attempt has been made to provide a complete overview or list of references. For further information on a specific molecule, the bi-monthly Berkeley Newsicter continues to be a good starting point. The 
printed Newsletter is essentially a bibliography of articles in the current journals on molecules comprising four or fewer atoms (contact jphillips@astro.berkeley .edu or spdavis@physics.berkeley.edu).

\section{Electronic spectra}

The laboratory astrophysics group at the CfA has continued to provide quantitative, high spectral resolution measurements of molecules of atmospheric and astrophysical interest in the ultraviolet. Theoretical studies of the predissociation of the Schumann-Runge ( $\mathrm{S}-\mathrm{R}$ ) bands of $\mathrm{O}_{2}$ have been carried out for both rotational ${ }^{10}$ and isotopjc dependency. ${ }^{11}$ Absorption bands of the $S-R$ system have been observed at $670 \mathrm{~K}$ at high resolution, and precise wavelength measurements have led to the molecular constants of the ground state of $\mathrm{O}_{2} \cdot{ }^{12}$ Two highly excited ${ }^{3}$ II states of $\mathrm{O}_{2}$ have been identified in collaboration with colleagues at the Photon Factory, Japan, and NRC, Canada. ${ }^{13}$ Absorption measurements at Ioppler limited resolution have been carried out by Yoshino and colleagues with a VUV Fourier transform spectrometer (FTS) in combination with a White cell at Imperial College (IC), London, U.K. The $\mathrm{O}_{2}$ Herzberg I band system $\left(A^{3} \Sigma_{u}^{+}-X^{3} \Sigma_{g}^{-}\right)$has been measured at a resolution of $0.06 \mathrm{~cm}^{-1} ;^{14}$ band oscillator strengths and rotational line strengths have been obtained. ${ }^{15}$ These are the first absorption intensity measurements of the Herzberg bands free of problems arising from inadequate spectral resolution. In addition, the NO $\delta(0,0)$ and $\beta(7,0)$ bands lave been measured at a resolution $0.06 \mathrm{~cm}^{-1}$ with the VUV FTS at IC. ${ }^{16}$ To extend the high resolution measurements to shorter wavelengths, the CfA/IC group moved this apparatus to the Photon Factory, Japan, where VUV radiation from a synchrotron source with a narrow band predisperser is avajlable. ${ }^{17}$ Analysis of the measurements of the $\mathrm{NO}$ bands and the $\mathrm{S}-\mathrm{R}$ bands of $\mathrm{O}_{2}$ obtained with this facility are in progress. The absorption cross sections for the VUV diffuse bands of $\mathrm{CO}_{2}{ }^{18}$ and $\mathrm{H}_{2} \mathrm{O}^{19}$ have been measured.

The VIV spectrum of $\mathrm{CO}$ continues to be intensively studied by several groups. The CfA group has obtained photoabsorption cross sections of $\mathrm{CO}$ in the wavelength region $92.5 \mathrm{mn}$ to $97.4 \mathrm{~nm}$ at $\sim 20 \mathrm{~K}$, thus greatly simplifying their application to astrophysical models. ${ }^{20}$ The band oscillator strengths of the $A\left(v^{\prime}\right)-X(0)$ fourth positive bands of $C O$ for $v^{\prime}=11-14$ have been obtained with high resolution ${ }^{21}$ and have confirmed the values of Chan et al. ${ }^{22}$ 'The Meudon group has also studied the $\mathrm{A}^{1} \Pi-\mathrm{X}^{1} \Sigma^{+}$transition for ${ }^{12}\left(\mathrm{C}^{18} \mathrm{O}\right.$ and ${ }^{13} \mathrm{C}^{18} \mathrm{O} \mathrm{C}^{23,24}$ Using the $\Lambda$ state term values a new set of term levels for the $B, C$ and $E$ states has been established. ${ }^{25}$

A new triplet state of $\mathrm{CO}\left(\mathrm{k}^{3} \mathrm{II}\right)$ has been analyzed through its interactions with the $\mathrm{E}$ and $\mathrm{B}$ states and by direct absorption measurements. ${ }^{26,27,28}$ The $\mathrm{B}^{1} \Sigma^{+}(v=3)$ level situated above the $\mathrm{B}^{1} \Sigma^{+}-\mathrm{D}^{\prime}{ }^{1} \Sigma^{+}$crossing has been observed and calculated with the semi-empirical potentials established earlier. ${ }^{29} \mathrm{~A}$ pulsed jet has been used in conjunction with the $10 \mathrm{~m}$ vacuum spectrograph and the BRV pulsed continuum to obtain cooled spectra of the CO Rydberg states. ${ }^{30}$

Predissociative and radiative lifetimes of the excited states of $\mathrm{CO}$ have been determined from line broadening moasurements on singly resolved rotational states using a coherent and tunable VUV source by Ubachs and co workers. ${ }^{31,32,33}$ For several states, the predissociation rates were found to depend on rotational state, parity and isotope. The $\mathrm{F}^{1} \mathrm{II} v=0$ and 1 levels were carefully studied for ${ }^{12} \mathrm{CO}$ and ${ }^{13} \mathrm{CO}$ and were found to be strongly predissoriated by the $\mathrm{k}^{3}$ II bound state. The lifetime of the $(4 p \pi) L^{1} \Pi n=0$ state ( $f$ parity) was determined at $1.0 \mathrm{~ns}$, typical of a radiative rather than a predissociative lifetime.

Basic spectroscopic work on the most important astrophysical molecule, $\mathrm{H}_{2}$, continues by the Meudon group. The photographic atlas of the Lyman and Werner bands has been published. ${ }^{34}$ More than 12000 lines are tabulated, $96 \%$ of which have a1 least one assignment. New calculations concerning the $B^{\prime}$ and 1) states have been published. ${ }^{35}$ Together with prevjous work concerning the $B$ and $(Y$, states these allow precise calculations of the Werner and Lyman bands. Comprehensive tables of line positions and intensities are now available. ${ }^{36,37}$ 
$\Lambda$ new set of molecular constants for the ground state of $\mathrm{N}_{2}$ has been established using all the data available in the different spectral ranges. ${ }^{38} \mathrm{~A}$ comprehensive model of the first seven singlet Rydberg and valence states has been established. This will allow precise modeling of the VUV emission of $\mathrm{N}_{2}$ in the atmosphere of Titan and the Earth around $100 \mathrm{~nm} .{ }^{39}$ The nf Rydberg levels of ${ }^{14} \mathrm{~N}_{2}$ converging on the $X^{2} \Sigma g_{g}^{+}$state of $\mathrm{N}_{2}^{+}$have been studied. ${ }^{40}$

Studies of the $\mathrm{N}_{2}^{+}$molecular ion have been made by the Berkeley group with a Pointolite arc which produces highly excited levels of the ion, and with a cooled hollow cathode lamp. The analysis was extended to much higher rotational energies as compared to the hollow cathode or furnace spectra. ${ }^{41}$ Bernath and co-workers used the Fourier Transform technique to study the electronic spectra of a number of astrophysically relevant molecules including $\mathrm{CoH}^{45}, \mathrm{CH}^{46}$ and the Swan system of $\mathrm{C}_{2} \cdot{ }^{47}$

Extensive electronic structure calculations continue to provide valuable information on potential energy surfaces, transition moments, spectroscopic constants and line intensities. A theoretical study of the NO $\epsilon$, the $11000 \AA$, and the $b^{4} \Sigma^{-}$bands has been made by the NASA-Ames group ${ }^{42,43,44}$, who also computed the electronic states of $\mathrm{MgC} .{ }^{49}$ The ground and excited states of $\mathrm{SiH}^{+152}$ and $\mathrm{CP}^{153}$ have been calculated by the Wuppertal group. Potential surfaces and line intensities of $\mathrm{Si}_{2} \mathrm{C}^{48}, \mathrm{~N}_{3}^{+},{ }^{50} \mathrm{NH}_{2}^{+},{ }^{51}$ and $\mathrm{CO}_{2}{ }^{52}$ have been investigated theoretically by the French group. The flat shape of the $\mathrm{N}_{3}^{+} \mathrm{X}^{3} \mathrm{\Sigma}_{g}^{-}$ground state along the asymmetric displacement coordinate leads to strong anharmonic resonances. For $\mathrm{NH}_{2}^{+}$, the quasilinear ground state and the bent quasi-linear $a^{1} A_{1}-b^{1} B_{1}$ Renner-Teller system have been studied up to high energies. An exhaustive study of the excited electronic states of $\mathrm{CO}_{2}$ suggests that the observed peculiar splittings of the first dipole-allowed electronic transition $1^{1} \Sigma_{u}^{+}-X^{1} \Sigma_{g}^{+}$are due to complex avoided crossings and vibronic coupling effects between the Rydberg and valence $1^{1} \Sigma_{u}^{+}$states.

The Leiden group has performed comprehensive theoretical calculations of the absorption spectra of the lowest 10 electronic states of $\mathrm{CH}_{2}$ and its isotopes. ${ }^{53-57}$ Similar work on $\mathrm{NH}_{2}$ is in progress. ${ }^{58}$ The $\mathrm{HCO}^{+}$ ion appears to be remarkably transparent to ultraviolet radiation, since all its dipole allowed transitions lie a.t very high energies. 59,60

The transition rates for $\mathrm{ZrO}$ have been measured from a laboratory absorption spectrum by the Berkeley group, for the purpose of resolving differences between an earlier analysis of an emission spectrum, and experimental results and theoretical treatments. ${ }^{61}$ The spectrum of LaS from a carbon tube furnace has been produced and analyzed. ${ }^{62}$ A major theoretical effort by Langhoff on the $g f$ values for all absorption lines of low-lying electronic states of $\mathrm{TiO}$ that would contribute to the opacity of cool evolved stars has just been finished. ${ }^{63,64}$

The SCAN data base by Jørgenson ${ }^{9}$ contains information about the identification, frequency, excitation energy and strength of $\sim 70$ million lines from the molecules $\mathrm{CN}, \mathrm{CH}^{65}, \mathrm{TiO}, \mathrm{H}_{2} \mathrm{O}, \mathrm{HCN}, \mathrm{C}_{2} \mathrm{H}_{2}$ and $\mathrm{C}_{3}$. The Harvard-Smithsonian data base on $\mathrm{TiO}, \mathrm{C}_{2}, \mathrm{SiO}, \mathrm{CN}, \mathrm{CO}, \mathrm{H}_{2}, \mathrm{CH}, \mathrm{NII}, \mathrm{OH}, \mathrm{MgII}$ and Sill was recently reviewed by Kurıcz. ${ }^{66}$

There has been major progress in experimental and theoretical studies of larger molecules. The photofragmentation of model PAll monocations such as deuterated naphtalene ${ }^{67}$ and benzene ${ }^{68}$ has been studied using synchrotron radiation in the range 15-35 eV. The effect of molecular size has been evaluated ${ }^{69}$ The single and double ionization potentials of PAH's lave been modeled by an empirical expression. ${ }^{70}$ The formation, relaxation and destruction of negative PAH ions has been st udied by an electron diffusion technique. ${ }^{71}$ The formation of PAH's in stellar envelopes has been modeled on the basis of the laboratory data, Small PAH's appear to be formed near the star and destroyed further out. Larger ones are formed at larger distances by condensation of the small PAH's produced initially. ${ }^{72,73} \mathrm{Ab}$ initio studies of the electronic absorption spectra of some PAH cations have been made in the Bonn group. ${ }^{57}$ 
The possibility that linear carbon chains are responsible for some of the diffuse interstellar bands has received renewed attention. ${ }^{74,75}$ Detailed absorption spectra of these chains and their cations in neon matrices have been obtained by Maier and co-workers. ${ }^{76-82}$ A possible assignment of two diffuse interstellar bands observed at near-infrared wavelengths with $\mathrm{C}_{60}^{+}$was made by Foing \& Ehrenfreund, ${ }^{83}$ based on spectra by Fulara et al. ${ }^{84}$ The electronic spectroscopy of $\mathrm{C}_{60}$ has been studied in the Meudon laboratory between 200 and $750 \mathrm{~nm}$ by electron energy loss spectroscopy. ${ }^{85,70}$ Rotational band contours of $\mathrm{C}_{60}$ and linear carbon chains have been calculated and compared to the diffuse interstellar bands. ${ }^{86}$ It is concluded that most. DIB's would be due to molecules containing more than 10 atoms provided the excited states are coupled with isoenergetic vibronic levels of lower electronic states.

\section{Vibrational spectra}

The vibrational transitions of $\mathrm{H}_{3}^{+}$continue to be a popular topic among infrared spectroscopists. A highlight is the definite detection of interstellar $\mathrm{II}_{3}^{+}$by Geballe \& Oka in absorption in the direction of deeply embedded protostars. ${ }^{87} \mathrm{H}_{3}^{+}$infrared emission lines were also detected in polar regions of Saturn. The lines are weaker than those in Jupiter by two orders of magnitude reflecting the lower plasma activity. ${ }^{88}$ On the spectroscopic side, Oka and co-workers have observed the near-infrared $3 \nu_{2}$ overtone band of $\mathrm{II}_{3}^{+}$at $1.4 \mu \mathrm{m}$ using InGaAsP communication diode lasers. ${ }^{89}$ Spectral lines and the distribution of $\mathrm{H}_{3}^{+}$in extremely high rotational levels have been studied for supplying data to astronomers. ${ }^{90}$ New experiments and analysis of the $\mathrm{H}_{3}^{+}$vibration-rotation spectra were also made by the NRC group in Canada, ${ }^{91}$ and by Maier's group. ${ }^{92}$ Spin selection rules in plasma chemistry of ortho- and para- $\mathrm{H}_{3}^{+}$has been experimentally demonstrated. ${ }^{93}$

Oka also reported on the infrared spectra of several other ions. The spectrum of $\mathrm{N}_{2} \mathrm{H}^{+}$in highly-excited vibrational states up $10600 \mathrm{~cm}^{-1}$ has been observed and analyzed 94 , as has the $\nu_{2}+\nu_{3}-\nu_{2}$ hot band of $\mathrm{NH}_{3}^{+95}$ and the infrared spectrum of $\mathrm{NH}_{2}^{+} .{ }^{96}$ The infrared spectrum of $\mathrm{CH}_{3}^{+}$involving high rotational levels has been observed and the rotational distribution studied. ${ }^{97}$ The spectrum of $\mathrm{C}_{2} \mathrm{H}_{3}^{+}$was measured using a hollow cathore discharge, and its chemistry analyzed..$^{98}$

The infrared work at the Herzberg Institute of Astrophysics has concentrated on the spectra of weaklybonded complexes, including $\mathrm{CO}-\mathrm{N}_{2},{ }^{99} \mathrm{CO}-\mathrm{He},{ }^{100}$ and the $\mathrm{HD}$ dimer. ${ }^{101}$ Fundamental infrared spectroscopy has been performed for the $\nu_{3}$ band of $\mathrm{C}_{3}$ isotopes, ${ }^{102} \mathrm{C}_{4},{ }^{103} \mathrm{CH}_{3} \mathrm{NC},{ }^{104}, \mathrm{CH}_{3} \mathrm{OH}$ isotopes, ${ }^{105-107}$ $\mathrm{C}_{2} \mathrm{H}_{2}$ and isotopes, ${ }^{109,109}$ and $\mathrm{C}_{3} \mathrm{O}_{2} \cdot{ }^{110}$. High resolution wave-number standards for the infrared have been published.111

Bernath and co-workers have used the Fourier transform method to measure the infrared spectra of a large number of stable and unstable species, including $\mathrm{ND}, \mathrm{PII},{ }^{112}$ hot $\mathrm{H}_{2} \mathrm{O},{ }^{113} \mathrm{HF},{ }^{114} \mathrm{SiO},{ }^{115} \mathrm{CS},{ }^{116}$ and $\mathrm{SH}^{117}$ Pure carbon molecules, including $\mathrm{C}_{60}$ and $\mathrm{C}_{70}$ have been discussed. ${ }^{118-120}$

Theoretical calculations of ground state potential energy surfaces and dipole moments have been made for $\mathrm{CO}^{121} \mathrm{MgO}^{+},{ }^{122} \mathrm{NO}^{45}{ }^{45} \mathrm{SiO},{ }^{123}$ and $\mathrm{C}_{2} \mathrm{H}_{2}^{+} \cdot{ }^{124}$ Theoretical infrared spectra for PAH's (neutral, cations and anions) have been computed by langhoff. ${ }^{25}$

\section{Rotational spectra}

Thaddeus lias reported six new carbon chains detected in the laboratory, all of astrophysical interest: $\mathrm{C}_{7} \mathrm{H}_{1}{ }^{126} \mathrm{C}_{8} \mathrm{H},{ }^{127} \mathrm{C}_{9} \mathrm{H},{ }^{128} \mathrm{C}_{11} \mathrm{H},{ }^{129} \mathrm{HC}_{11} \mathrm{~N},{ }^{130}$ and $\mathrm{HC}_{13} \mathrm{~N} .{ }^{131}$ The microwave and millimeter wave frequencies of these molecules are now known to a fraction of $1 \mathrm{~km} \mathrm{~s}^{-1}$ in radial velocity. $\mathrm{HC}_{11} \mathrm{~N}$, which for 14 years has stood as the largest interstellar molecule, was unfortunately misidentified. The claimed lines in IRC +10216 and TMC 1 are some entirely different molecule - the actual lines of $\mathrm{HC}_{11} \mathrm{~N}$ lie $0.13 \%$ 
lower in frequency, and are so far undetected. However, $\mathrm{C}_{8} \mathrm{H}$ has been identified in $\mathrm{IRC}+10216$ on the basis of the laboratory data, ${ }^{127}$ and it seems likely that some or all of the other chains on this list will be detected in the fairly near future. The CfA/Harvard group has also been involved in investigating other species, including $\mathrm{N}_{2} \mathrm{H}^{+},{ }^{132} \mathrm{C}_{4} \mathrm{H},{ }^{133} \mathrm{C}_{3} \mathrm{~N},{ }^{134}$ and $\mathrm{HC}_{3} \mathrm{~S}^{135}$

The submillimeter spectra of Orion $/ \mathrm{KL}^{6}$ and other so called "hot core" objects require detailed sper troscopy of complex organic molecules up to high frequencies. De Lucia, Herbst and co-workers have studied the submillimeter spectra of $\mathrm{CH}_{3} \mathrm{OD},{ }^{136} \mathrm{CH}_{3} \mathrm{CHCH}_{2},{ }^{137} \mathrm{C}_{2} \mathrm{H}_{5} \mathrm{CN},{ }^{138}$ trans- and gauche ethylalcohol, ${ }^{139,140}$ and $\mathrm{DCOOCH}_{3} \cdot{ }^{141}$ Spectra up to the terahertz region have been measured it the Cologne laboratory of $\mathrm{SO},{ }^{142} \mathrm{CN},{ }^{143}$ and $\mathrm{CH}_{3} \mathrm{OH},{ }^{144}$ and in Lille of $\mathrm{NH}_{3} \cdot{ }^{146}$ The microwave spectra of the simplest amino acid, glycine, have recently been measured by Lovas' group ${ }^{145}$ for both conformers, enabling new astronomical searches.

The Lille group has also measured millimeter spectra of $\mathrm{HCOCN},{ }^{147} \mathrm{H}_{2} \mathrm{SiO},{ }^{148} \mathrm{Si}_{2} \mathrm{H}_{2},{ }^{149} \mathrm{C}_{2} \mathrm{H}_{3}^{+},{ }^{150}$ and $\mathrm{NH}_{2} \cdot{ }^{151}$

\section{References}

1. Parkinson, W.F., 1992, in Atomic and Molecular Data for Space Astronomy, ed. P.L. Smith \& W.I. Wiese (Springer, Berlin), 149; See WWW: http://cfa-øws.harvard.edu/amp/data/

2. Rothman, L.S., et al., 1992, J. Quant. Spectrose. Rad. Transfer 48, 469; available on CD-ROM, and integra.ted in ref. 3.

3. Chance, K., Jucks, K.W., Johnson, D.G., and Traub, W.A., 1994, J. Quant. Spectrosc. Rad. Transf. 52, 447; See WWW: http://firs-www .harvard .edu/

4. Poynter, R.L., and Pickett, H., 1985, Appl. Optics 24, 2335; See WWW: http://spec.jpl.nasa.gov/

5. Lovas, F.J., 1992, J. Phys. Chem. Ref. Data 21, 181; See WWW: http://physics.nist.gov/PhysRefData/

6. Schilke, P., Groesbeck, T., Blake, G.A., and Phillips, T.G., 1996, Astrophys. J. Suppl., in press.

7. Crovisier, J., 1992, Constants for molecules of astrophysical interest in the gas phase: photodissociation, microwane and infrared spectra, Obs. de Meudon.

8. Hinkle, K., Wallace, L., and Livingston, W., 1995, Infrared atlas of the Arcturus spectrum 0.9 5.3 $\mu \mathrm{m}$ (ASP, SaIt Francisco); available by anonymous ftp to 140.252.1.11 in /pub/hires_k_band and /pub/1oures_k_band.

9. Jørgenson, U.G., in Molecules in A strophysics: probes and processes, IAU Symposium 178, ed. F..F. van Dishoeck (Kluwer, Dordrecht), in press; The SCAN data base is available by anonymous ftp to stella.nbi.dk in /pub/scan.

10. Cheung, A.S-C., Mok, D.K-W., Jamieson, M.J., Finch, M., Yoshino, K., Dalgarno, A., and Parkinson, W.H., 1993, 1. Chem. Phys. 99, 1086.

11. Cheung, A.S-C., Mok, D.K-W., Yoshino, K., Parkinson, W.H., Jamieson, M.J., Dalgarno, A., and Child, M.S., 1995, J. Chem. Phys. 103, 2369.

12. Cheung, A.S-C., Yoshino, K., Esmond, J.R., and Parkinson, W.H., 1996, J. Molec. Spectrosc., in press.

13. It.o, K., Huber, K.P., Yoshino, K., Ogawa, M. and Morioka, Y., 1995, J. Molec. Spectrosc. 171, 1.

14. Yoshino, K., Murray, J.E., Esmond, J.R,, Sun, Y., Parkinson, W.H., Thorne, A.P., Learner, R.C.P., and (ox, (i., 1994, Can. J. Phys. 72, 1101.

15. Yoshino, K., Esmond, J.R., Murray, J.E., Parkinson, W.H., Thorne, A.P., Learner, R.(:.M., and Cox, (A., 1995, , (. (htm. Phys. 103, 1243.

16. Murray, J.E., Yoshino, K., Esmond, J.R., Parkinson, W.H., Sun, Y., Dalgarno, A., Thorne, A.P., and ('ox, (7. 1994, J. Chem. Phys. 101, 62.

17. Yoshino, K., Smith, P.L., Parkinson, W.H., Thorne, A.P., and lto, K., 1995, Rev. Scient. Instr. 66, 2122.

18. Yoshino, K., Esmond, J.R., Sun, Y., Parkinson, W.H., Ito, K. \& Matsui, T., 1996, J. Quant. Spectrosc. Rad. Transf. 55. 53.

19. Yoshino, K., Esmond, J.R., Parkinson, W.H., Ito, K., and Matsui, M., 1996, Chem. Phys., in press.

20. Yoshino, K., Stark, G., Esmond, J.R., Smith, P.L., Ito, K., and Matsui, M., 1995, Astrophys. J. 438, 1013.

21. Smith, P.L., Stark, G., Yoshino, K., and Tto, K., 1994, Astrophys. J. 431, L143.

22. Chan, W.F., Cooper, G., and Brion, C.E., 1993, Chem. Phys. 170, 123.

23. Haridass, C., Paddi Reddy, S., and Le Floch, A., 1994, J. Mol. Spectrosc. 167, 334.

24. Beaty, L.M., Braun, V.D., Huber, K.P., and Le Floch, A., 1996, Astrophys. J., in press.

25. Haridass, C., Paddi Reddy, S., and Le Floch, A., 1994, J. Mol. Spectrosc, 168, 429.

26. Baker, J., Lemaire, J.L., Couris, S., Vient, A., Malmasson, D., and Rostas, F., 1993, Chem. Phys. 178, 569

27. Baker, J., 1994, J. Mol. Spectrosc. 167, 323.

28. Baker, J., and Launay, F., 1994, J. Mol. Spectrosc. 165, 75.

29. Baker, J., Tchang-Brillet, W.-ÜL., and Julienne, P., 1995, J. Chem. Phys. 102, 3956

30. Rostas, F., Launay, F., Eidelsberg, M., Benharrous, M., Blaess, C., and Huber, K.P., 1994, Can. 1. Phys. 72. 913

31. Eikema, K.S.E., Hogervorst, W., and Ubachs, W., 1994, Chem. Phys. 181, 217.

32. Ubachs, W., Eikema, K.S.E., Levelt, P.F., Hogervorst, W., Drabbels, M., Meeris, W.L. \& ter Menlen, J.J., 1994, Ap.J 427, L55. 
33. Cacciani, P., Hogervorst, W., and Ubachs, W., 1995, J. Chem. Phys. 102, 8308.

34. Roncin, J.-Y., and Launay, F., 1994, J. Phys. Chem. Ref. Data, monograph 4.

35. Abgrall, H., Roueff, E., Launay, F., Roncin, J.-Y., and Subtil, J.L., 1993, J. Mol. Spectrosc. 157, 512.

36. Abgrall, II., Roueff, E., Launay, F., Roncin, J.-Y., and Subtil, J.L., 1993, Astron. Astrophys. 101, 273.

37. Alggrall, Il., Roueff, E., Launay, F., Roncin, J.-Y., and Subtil, J.L., 1993, Astron. Astrophys. 101, 323.

38. Edwards, S., Roncin, J.-Y., Launay, F., and Rostas, F., 1993, J. Mol. Spectrosc. 162, 257.

39. Fdwards, S.A., Tchang- Brillet, W.-UL., Roncin, J.-Y., Launay, F., and Rostas, F., 1995, Planet. Space Sci. 43, 67

40. Huber, K.P., Jungen, Ch., Yoshino, K., Ito, K., and Stark, G., 1994, J. Chem. Phys. 100, 7957.

41. Javis, S.P., Nguyen, A.-D., Michaud, F., and Roux, F., 1996, Appl. Opt. 35, 2867.

42. Sheehy, J.A., Bauschlicher, C.W., Langhoff, S.R., and Partridge, H., 1994, Chem. Phys. Lett. 225, 221.

43. Banschlicher, C.W., Partridge, H., and Langhoff, S.R., 1993, Chem. Phys. Lett. 211, 312.

44. Langhoff, S.R., Banschlicher, C.W., and Partridge, H., 1994, Chem. Phys. Lett. 223, 416.

45. Ram, R.S., Bernath, P.F., and Davis, S.P., 1996, J. Molec. Spectrosc. 175, 1.

46. Bernath, P.F., 1994, J. Mol. Spectrosc. 165, 301.

47. Prasad, C.V.V., and Bernath, P.F., 1994, Astrophys. J. 426, 812.

48. Spielfiedel, A., Carter, S., Feautrier, N., Chambaud, G., and Rosmus, P., 1996, J. Phys. Chem. 100, 10055.

49. Bauschlicher, C.W., Janghoff, S.R., and Partridge, H., 1993, Chem. Phys. Lett. 216, 341.

50. Chambaud, G., Rosmus, P., Bennet, F., Maier, J.P., Spielfiedel, A., 1994, Chem. Phys. Lett. 231, 9.

51. Chambaud, G., Schmelz, T., Gabriel, N., Rosmus, P., Spielfiedel, A., and Feautrier, N., 1993, Theor. Chim. Acta $87,5$.

52. Spielfiedel, A., Feautrier, N., Chambaud, G., Rosmus, P., and Werner, H.J., 1993, Chem. Phys. Lett. $216,162$.

53. Beärda, R.A., van Hemert, M.C., and van Dishoeck, E.F., 1995, J. Chem. Phys. 102, 8930.

54. Kroes, (..-J., van Dishoeck, F.F., Beärda, R.A., and van Hemert, M.C., 1993, J. Chem. Phys. $99,228$.

55. Beärda, R.A., Kroes, G.-J., van Hemert, M.C., Heumann, B., Schinke, R., and van Dishoeck, E.F., 1994, J. Chem. Phys. 100,1113

56. van Dishoeck, E.F., Beärda, R.A., and van Hemert, M.C., 1996, Astron. Astrophys. 307, 645.

57. Niederalt, C., Grimme, S., and Peyerimhoff, S.D., 1995, Chem. Phys. Lett. 245, 455.

58. Vetter, R., Zülicke, L., Koch, A., van Dishoeck, E.F., and Peyerimhoff, S.P., 1996, J. Chem. Phys. $104,5558$.

59. Koch, A., van Dishoeck, E.F., and van Hemert, M.C., 1995, Bursenges. Phys. Chem. 99, 393.

60. Koch, A., van IIemert, M.C., and van Dishoeck, E.F., 1995, J. Chem. Phys. 103, 7006.

61. Wittleton, J.E., Davis, S.P., and Song, M., 1993, Astrophys. J. 404, 412.

62. Winkel, R..J., David, S.P., and Abrams, M.C., 1996, Appl. Opt. 35, 2874.

63. Langhoff, S.R., 1996, Astrophys. J., submitted.

64. Langhoff, S.R., 1996, in Molecules in Astrophysics: probes and processes, IAU Symposium 178, ed. E.F. van Dishoeck (Kluwer, Dordrecht), in press.

65. Jørgensen, U.G., J,arsison, M., Iwamae, A., and Yu, B., 1996, Astron. Astrophys., in press.

66. Kurucz, R.L., 1994, in Molecules in the Stcllar cnvironment, ed. U.G. Jørgenson, Lecture Notes in Physics 428 (Springer, Berlin)

67. Jochins, II.W., Rasekh, H., RuhI, E., Baumgartel, H., and Leach, S., 1993, J. Phys. Chem. 97, 1312.

68. Braithart, O., Tobita, S., Roy, P., Nenner, I., Lablanquie, P., Hagan, D., and Leach, S., 1993, Int. J. Mass. Spectrom. Ion. Phys. 124, 185.

69. Jochims, H.W., Ruhl, E., Baumgartel, H., Tobita, S., and Leach, S., 1994, Astrophys. J. 420, 307.

70. Leach, S., 1995, Planet. Space Sci. 43, 1153.

71. Tobita, S., Leach, S., Jochims, It.W., Rïhl, F., Illenberger, E., and Baumgärtel, H., 1994, Can. J. Phys. 72, 1060.

72. Allain, T., Sedlmayr, E., and Leach, S., 1995, Astrophys. Space Sci. 224, 417.

73. Allain, T., leach, S., and Sedlmayr, F., 1996, Astron. Astrophys. 305, 602.

74. Fulara, J., Lessen, D., Freivogel, P., and Maier, J.P., 1993, Nature 366, 439.

75. Freivogel. P., Fulara, J., and Maier, J.P., 1994, Astrophys. J. 431, L151.

76. Freivogel, P., Fulara, J., Lessen, D., Forney, D., and Maier, J.P., 1994, Chem. Phys. 189, 335.

77. Forney, D., Freivogel, P., Fulara, J., and Maicr, J.P., 1995, J. Chem. Phys. 102, 1510.

78. Forney, D., Fulara, J., Freivogel, P., Jakobi, M., Lessen, D., et al., 1995, J. Chem. Phys. 103, 48.

79. Freivogel, ''., Fulara., J., Jakobi, M., Forney, 1)., and Maier, J.P., 1995, J. Chem. Phys. 103, 54.

80. Fulara, J., Freivogel, P., Forncy, D., and Maier, J.P., 1995, J. Chem. Phys. 103, 8805.

81. Freivogel, P., Grutter, M., Forney, D., and Maier, J.P., 1996, Chem. Phys. Lett. 249, 191.

82. Forney, D., Freivogel, P., Grutter, M., and Maier, J.P., 1996, J. Chem. Phys. 104, 4954.

83. Foing, B.H., and Ehrenfreund, P., 1994, Nature 369, 296.

84. Fulara, J., Jakobi, M., and Maier, J.P., 1993, Chem. Phys. Lett. 211, 227.

85. Bulliard, C., Allan, M., and Leach, S., 1993, Chem. Phys. Lett. 209, 434.

86. Edwards, S., and Leach, S., 1993, Astron. Astrophys. 272, 533.

87. Geballe, T.R., and Oka, T., 1996, Nature, submitted.

88. Geballe, T.R., lagod, M.-F., and Oka, T., 1993, Astrophys. J. 408, L109.

89. Ventrudo, B.F., Cassidy, D.T., Guo, Z.Y., Joo, S.W., Lee, S.S., and Oka, T., 1994, J. Chem. Phys. $100,6263$.

90. Uy, D., Cabrys, C.M., Jagod, M.-F., and Oka, T., 1994, J. Chem. Phys. 100, 6267.

91. Majewski, W.A., McKellar, A.R.W., Sadovskii, D., and Watson, J.K.G., 1994, Can. J. Phys. $72,1016$.

92. Feher, M., Rohrbacher, A., and Maier, J.P., 1994, Chem. Phys. 185, 357.

93. Uy, I)., Cordonnier, M., and Oka, T., 1996, Nature, submitted.

94. Kabbadj, Y., Huet. T.R., Rehfuss, B.I), Gabrys, C.M., and Oka, 'T., 1994, J. Mol. Spectrosc. $163,180$. 
95. Huet, T.R., Kabbadj, Y., Gabrys, C.M., and Oka, T., 1994, J. Mol. Spectrosc. 163, 206.

96. Kabbadj, Y., Huet, T.R., Uy, D., and Oka, T., 1996, J. Mol. Spectrosc. 175, 277.

97. Jagod, M.-F., Gabrys, C.M., Rösslein, M., Uy, D., and Oka, T., 1994, Can. J. Phys. 72, 1192.

98. Gabrys, C.M., Uy, D., Jagod, M.-F., Oka, T., and Amano, T., 1995, J. Phys. Chem. 99, 15611.

99. Xu, Y.J., and McKellar, A.R.W., 1996, J. Chem. Phys. 104, 2488.

100. Chuaqui, C.E., Leroy, R.J., and McKellar, A.R.W., 1994, J. Chem. Phys. 101, 39.

101. McKellar, A.R.W., 1994, Can. J. Phys. 72, 215.

102. Moazzenahmadi, N., and McKellar, A.R.W., 1993, J. Chem. Phys. 98, 7757.

103. Moazzenahmadi, N., 'Thong, J.J., and McKellar, A.R.W., 1994, J. Chem. Phys. 100, 4033.

104. Pliva, J., Le, L.D., Johns, J.W.C., Lu, Z., and Bernheim, R.A., 1995, J. Moler. Spertrosc. 173, 423.

105. Mukhopadhyay, 1., Lees, R.M., Lewisbevan, W., and Johns, J.W.C., 1995, J. Chem. Phys. 102, 6444.

106. Lees, R.M., Goulding, R.R.J., Zhao, S.B., Mukhopadhyay, I., and Johns, J.W.C., Int. J. Infrared 15, 2021.

107. Mollabashi, M., Lees, R.M., and Johns, J.W.C., 1993, Int. J. Infrared 14, 1727.

108. Dilonardo, G., Ferracuti, P., Fusina, L., Venuti, E., and Johns, J.W.C., 1993, J. Molec. Spectrosc. 161, 466.

109. Sarma et al., 1995, J. Molec. Spectrosc. 173, 574.

110. Vanderauwera, J., Holland, J.K., Jensen, P., and Johns, J.W.C., 1994, J. Molec. Spectrosc. 163, 529.

111. Guelachvili, H., et al., 1996, J. Molec. Spectrosc. 177, 164.

112. Ram, R.S., and Bernath, P.F., 1996, J. Molec. Spectrosc. 176, 329.

113. Polyansky, O.I., Busler, J.R., Guo, B.J., Zhang, K.Q., and Bernath, P.F., 1996, J. Molec. Spectrose. 176, 305.

114. Ram, R.S., et al., 1996, Astrophys. J. Suppl. 103, 247.

115. Campbell, J.M., Klapstein, D., Dulick, M., and Bernath, P.F., 1995, Astrophys. J. Suppl. 101, 237.

116. Ram, R.S., Bernath, P.F., and Davis, S.P., 1995, J. Molec. Spectrosc. 173, 146.

117. Ram, R.S., Bernath, P.F., Engleman, R., and Brault, J.W., 1995, J. Molec. Spectrosc. 172, 34

118. Nemes, L., et al., 1994, Chem. Phys. Lett. 218, 295.

119. Bernath, P.F., 1994, Adv. Space. Res. 15, 15.

120. Clayton, G.C., et al., 1995, Astronom. J. 109, 2096.

121. Langhoff, S.R., and Bauschlicher, C.W., 1995, J. Chem. Phys. 102, 5220.

122. Bauschlicher, C.W., Langhoff, S.R., and Partridge, H., 1994, J. Chem. Plys. 101, 2644.

123. Langhoff, S.R., and Bauschlicher, C.W., 1993, Chem. Phys. Lett. 211, 305

124. Peric, M., and Peyerimhoff, S.D., 1995, J. Chem. Phys. 102, 3685.

125. Langhoff, S.R., 1996, J. Phys. Chem. 100, 2819.

126. Travers, M.J., McCarthy, M.C., Gottlieb, C.A., and Thaddeus, P., 1996, Astrophys. J. 465, 1.77.

127. McCarthy, M.C., Travers, M.J., Kovacs, A., Gottlieb, C.A., and Thaddens, P., 1996, Astron. Astrophys. 309, L.31.

128. McCarthy, M.C., et al., 1996, Astrophys. J. Letters, in press.

129. McCarthy, M.C., et al, 1996, Science, submitted.

130. Travers, M.J., et al., 1996, Astrophys. J. Letters, submitted.

131. To be submitted to Astrophys. J. Letters.

132. Caselli, P., Myers, P.C., and Thaddeus, P., 1995, Astrophys. J. 455, L77.

133. Chen, W., Novick, S.E., McCarthy, M.C., Gottlieb, C.A., and Thaddeus, P., 1995, J. Chem. Phys. $103,7828$.

134. McCarthy, M.C., Gottlieb, C.A., Thaddeus, P., Horn, M., and Botschwina, P., 1995, I. Chem. Phys. 103, 7820.

135. McCarthy, M.C., et al., 1994, Astrophys. J. 431, L127.

136. Anderson, T., Herbst, E., and De Lucia, F.C., 1993, J. Molec. Spectrosc. 159, 410.

137. Pearson, J.C., Sastry, K.V.L.N., Herbst, F., and De Lucia, F.C., 1994, .I. Molec. Spectrosc. 166, 120.

138. Pearson, J.C., Sastry, K.V.L.N., Herbst, E., and De Lucia, F.C., 1994, Astrophys. J. Suppl. 93, 589.

139. Pearson, J.C., Sastry, K.V.L.N., Winnewisser, M., Herbst, E. \& De Lucia, F.C., 1995, J. Phys. (Chem. Ref. Data $24,1$.

140. Pearson, J.C., Sastry, K.V.L.N., Herbst, E., and De Lucia, F.C., 1996, J. Molec. Spectrosc. 175, 246.

141. Oesterling, L.C., Ferguson, D.W., Herbst, E., and De Lucia, F.C., 1995, J. Mol. Spectrosc. $172,469$.

142. Klaus, T., Belov, S.P., Saleck, A.H., Winnewisser, G., and Herbst, E., 1994, J. Molec. Spectrosc. $168,235$.

143. Klisch, E., Klaus, T., Belov, S.P., Winnewisser, G., and Herbst, E., 1995, Astron. Astrophys. 304, L5.

144. Belov, S.P., Winnewisser, G., and Herbst, E., 1995, J. Molec. Spectrosc.. 174, 253.

145. Lovas, F.J., Kawashima, Y., Grabow, J.U., Suenram, R.D., Fraser, G.T., et al., 1995, Astrophys. J. 455 , I.201.

146. Krupnov, A.F., et al., 1996, J. Molec. Spectrosc. 176, 442 .

147. Bogey, M., Demuynck, C., Destombes, J.L., and Vallee, Y., 1995, J. Molec. Spectrosc. 172, 344.

148. Bailleux, S., Bogey, M., Demuynck, C., Destombes, J.L., and Walters, A., 1994, J. Chem. Phys. 101, 2729.

149. Bogey, M., et al., 1994, J. Chem. Phys. 100, 8614 .

150. Bogey, M., Cordonnier, M., Demuynck, C., and Destombes, J.L., 1992, Astrophys. J. 399, L103.

151. Huet, T.R., et al., 1996, Astron. Astrophys. 311, 343.

152. Sannigrahi, A.B., Buenker, R.J, Hirsch, G., and Gn, J.P., 199.5, Chem. Phys. Lett. 237, 204.

153. Gu, J.P., Buenker, R.J., and Hirsch, G., 1994, Chem. Phys. 185, 39. 


\title{
WORKING GROUP 6: MOLECULAR REACTIONS ON SOLID SURFACES
}

\author{
Sydney Leach, Chair
}

Since the last Report there has been considerable recognition of the astrophysical importance of interstellar, interplanetary, and cometary dust and their function as sources of cosmochemical reactions. Laboratory studies and simulations, as well as increasing observation of interstellar, interplanetary and cometary materials have developed in number and in depth. It is noticeable that this area has become attractive to surface science scientists as evidenced by their participation in recent workshops and meetings. However, so far, in spite of their relevance to astrophysical problems, relatively few laboratory studies have been directed towards the chemical aspects of those molecular reactions on solid surfaces. This report therefore deals mainly with physical and physico-chemical properties of materials within this context. As was the last, the present report is non-exhaustive and seeks to give indications to key studies in this area. Basic references to surface science studies and techniques were given in the last Report.

\section{Reviews and Meetings}

(i) Physical and Chemical processes in Icy Grain Mantles [Schmitt, B.: 1994, Molecules and Grains in Space: AIP Conf. Proc. 312, 735].

(ii) Nenner, I. (ed.).: 1994, Molecules and Grains in Space: AIP Conf. Proc. 312, pp.1-863.

(iii) Millar, T.J. and Williams, D.A.(eds.): 1993, Dust and Chemistry in Astronomy, (IOP, Bristol).

(iv) Cosmic Chemistry: Molecules in Space, Williams, D.A.: 1994, Contemporary Physics 35, 269-283.

(v) Circumstellar Matter. Watt, G.D. and Williams, P.M. (eds.): 1995, Circumstellar Matter, (Kluwer, Dordrecht).

(vi) Shocks in Astrophysics. Millar, T.J. and Raga, A.C. (eds.): 1995, Shocks in Astrophysics, (Kluwer, Dordrecht).

(vii) International Conference on Dust, Molecules and Backgrounds: From Laboratory to Space, 1995 (October issue), Planet. Space. Sci. 43.

\section{Studies of Dust Grain Properties and Models}

Composition and radiative properties of grains in molecular clouds and accretion disks [85]; dust destruction mechanisms [19]; dust temperatures [103]; size distribution of dust particles [52]; modelling of processes from molecules to grains [101]; dust opacity and condensation models [39]; grain alignment processes in dark clouds $[32,114]$; nova dust evolution and formation of HAC emission features [27]; formation of complex molecules on grain surfaces [42, 75]; chemical models involving gas-grain interactions $[8,37]$; grains and shocks $[28,29]$.

\section{Astrophysical Observations}

Observations of hot amorphous carbon grains [119]; observations of high galactic latitude dust. [50, 87, 104]; silicate cosmic dust observations and analogues [45, 54, 105]; possible detection of solid formaldehyde in the interstellar medium [100]; solid CO in Taurus Dark Cloud [18].

\section{Laboratory Studies and Astrophysical Modelling of Carbonaceous Materials}

Formation of carbon-based grains in the outflows of Red Giants: modelling $[1,2,13,17,34]$; photoelectric heating mechanisms of very small graphitic grains and polycyclic aromatic hydrocarbons (PAHs) [5]; coal model for the UV-visible interstellar extinction curve [36, 80-82]; laboratory spectra of PAH molecules and ions and the extinction curve $[58,59,92,93]$; origins of variation of the $2175 \mathrm{~A}$ band in the interstellar extinction curve [64]; laboratory studies of carbon particles and clusters $[9,12,20-23,53,55,68-72,88$ 91]; evolution of dust particles in dense clouds [111]; vibrational excitation of $\mathrm{H}_{2}$ desorbed from a carbon surface [96]; molecular desorption from dust in star-forming regions [116]; $\mathbf{I I}_{2}$ formation on carbonaceous 
grains [24]; $\mathrm{H}_{2}$ formation on carbonaceous grains and release of mantle materials [117]; evolution of IIAC grains in interstellar medium $[26,27,107]$.

\section{Laboratory Studies and Astrophysical Modelling of Other Materials}

Condensation of oxides in M-star envelopes [7]; structural evolution in thermally processed silicates [110]; growth of SiC grains [49]; hydrogen cyanide polymers in the laboratory and in space [61,63]; iron-aromatic molecule chemistry in interstellar clouds [10,62]; gas-grain chemistry in protosolar nebula [77].

\section{Astrophysical Ices: Laboratory Studies and Astrophysical Observations}

Ion irradiation of model ices $[46,51,76,106]$; photochemical studies $[44,94,98]$; astrophysical observations $[6,86,99]$; evidence for chemical processing in pre-cometary icy grains in circumstellar environments of pre-main sequence stars [108]; UV desorption from water ice [113]; icy grain mantles and dust/gas chemical modelling [102]; photodesorption of $\mathrm{CO}$ ices [38]; mantle desorption processes driven by cosmic rays [115]; water ice formation on interstellar carbon dust [25]; high density water ice and its role in formation of icy mantles $[47,48]$.

\section{Interplanetary Dust Particles, Micrometeorites and Meteorites}

Interplanetary dust particles: observation and harvesting in the Antarctic [65], reactions in the Earth's atmosphere [66, 67]; origin of micrometeorites and meteorites [11]; interstellar grains in meteorites [79]; laboratory comparisons of organic materials to interstellar dust and meteorites [57, 83, 84, 95]; laboratory simulation of microdiamonds in space [22]; interstellar and circumstellar grains in meteorites [3, 4, 43]; formation of iron meteorites [30]; formation of oxides in carbonaceous chondrites [35].

\section{Other Relevant Topics}

Comets as reflection of interstellar medium chemistry [33]; Pre-biotic chemistry in space [60]; Large organic molecules in the interstellar gas [56, 109]; Photochemistry in dark clouds [14-16]; Jiffuse interstellar bands: Review [41]; Constraints on the identification of the diffuse interstellar bands [40]; Laboratory evidence for highly unsaturated hydrocarbons as carriers of some of the diffuse interstellar bands [31].

\section{References}

1. Allain, 'T., Leach, S. and Sedlmayr, E.: 1996, Astron. Astrophys. 305, 602.

2. Allain, T., I,each, S. and Sedlmayr, E.: 1996, Astron. Astrophys. 305, 616.

3. Amari, S., Lewis, R.S., and Anders, E.: 1994, Geochim. Cosmochim. Acta 58, 459.

4. Anders, E. and Zinner, E.: 1993, Meteoritics 28, 490.

5. Bakes, E.I.O. and Tielens, A.G.G.M.:1994, Astrophys. J. 427, 822.

6. Baratta, G.A. and Strazulla, G.: 1990, Astron. Astrophys. 240, 429.

7. Begemann, B., Henning, Th., Mutschke, H., and Dorschner, J.: 1995, Planet. Space. Sci. 43, 1257.

8. Bergin, E.A., Janger, W.D., and Goldsmith, P.F.: 1995, Astrophys. J. 441, 222.

9. Blanco, A., Bussoletti, E., Colangeli, L., Fonti, S., Mennella, V., and Stephens, J.R.: 1995, Planet. Space. Sci. $43,1227$.

10. Boissel, P.: 1994, Molecules and Grains in Space: AIP Conf. Proc. 312, 699.

11. Brownlee, D.: 1994, Analysis of Interplanetary Dust, A.I.P. Conf. Proc. 310, 5.

12. Buchta, C., D'Alessio, A., D’Anna, A., Gambi, G., Minutolo, P., and Russo, S.: 1995, Planet. Space. Sci. $43,1227$.

13. Cadwell, B.J., Wang, H., Feigelson, E.D., and Frenklach, M.: 1994, Astrophys. J. 429, 285.

14. Cecchi-Pestellini, C., Cervetto, C., Aiello, S., and Barsella, B.: 1995, Planet. Space. Sci. 43, 1319.

15. Cecchi-Pestellini, C., Aiello, S., and Barsella, B.: 1995, Mon. Not. R. Astron. Soc. 274, 134.

16. Cecchi-Pestellini, C., Aiello, S., and Barsella, B.: 1995, Astrophys. J. Suppl. 100, 187.

17. Cherchneff, I. , Barker, J.R., and Tielens, A.G.G.M.: 1992, Astrophys. J. 401, 269.

18. Chiar, J.E., Adamson, A.J., Kerr, T.H., and Whittet, D.C.B.: 1995, Astrophys. J. 455, 234.

19. Clark, F.O., Shipman, R.F., Assendorp, R., Kester, D., and Egan, M.P.: 1995, Planet. Space. Sci. 43, 1353.

20. Colangeli, L., Mennella, V., Palumbo, P., Rotundi, A., and Bussoletti, E.: 1995, Astrophys. J. Suppl. $113,1$. 
21. Colangeli, L., Mennella, V., Blanco, A., Fonti, S., Bussoletti, F., Gumlich, H.E., Mertens, H.C., and Jung, Ch.: 1993, Astrophys. J. 418, 435 .

22. Colangeli, L., Mennella, V., Bussoletti, E., Merluzzi, P., Palumbo, P., and Rotundi, A.: 1995, Planet. Space. Sci. 43, 1263.

23. Colangeli, L., Mennella, V., Stcphens, J.R., and Bussoletti, E.: 1994, Astron. Astrophys. 284, 583.

24. Duley, W.W. and Willians, D.A.: 1993, Mon. Not. R. Astron. Soc. 260, 37.

25. Juley, W.W. and Williams, D.A.: 1995, Mon. Not. R. Astron. Soc. 272, 442.

26. Duley, W.W., Jones, A.P., Taylor, S.D., and Williams, D.A.: 1993, Mon. Not. R. Astron. Soc. 260, 415.

27. Evans, A. and Rawlings, J.M.C.: 1994, Mon. Not. R. Astron. Soc. 269, 427.

28. Flower, T.R. and Pineau des Forts, G.: 1994, Mon. Not. R. Astron. Soc. 268, 724.

29. Flower, D.R., Pjneau des Forts, G., and Walmsley, C.M.: 1995, Astron. Astrophys. 294, 815

30. Franchi, I.A. and Pillinger, C.T.: 1993, Geochim. Cosmochim. Acta 57, 3105.

31. Fulara, S.J., Lessen, D., Freivogel, P., and Maier, J.P.: 1993, Nature 366, 439.

32. Gerakines, P.A. and Whittet, D.C.B.: 1995, Planet. Space. Sci. 43, 1325.

33. Greenberg, J. and Shalabica, O; 1994, in Asteroids, Comets and Meteors, IAU Symposium No. 160, (Klewer, Dordrecht), pp. 327-342.

34. Goeres, A.: 1993, Rev. Mod. Astron, 6, 165.

35. Greshake, A., Bischoff, A., Putnis, A., and Palme, H.: 1996, Science 272, 1316.

36. Guillois, O., Papoular, R., Reynaud, C., and Nenner, I.: 1994, Molecules and Grains in Space: AIP Conf. Proc. $312,817$.

37. Hasegawa, T.I. and Herbst, E.: 1993, Mon. Not. R. Astron. Soc. 261, 83; 263, 589.

38. Hellner, L., Dujardin, G., Hirayama, T., Philippe, L., Ramage, M.J., Gomtet, G., and Rose, M.: 1994, Molecules and Grains in Space: AIP Conf. Proc. 312, 773.

39. Henning, Th., Michel, B., and Stognienko, R.: 1995, Planet. Space. Sci. 43, 1333.

40. Herbig, G.H.: 1993, Astrophys. J. 407, 142.

41. Herbig, G.H.: 1995, Ann. Rev. Astron. Astrophys, 33, 19.

42. Hiraoka, K., Ohashi, N., Kihara, Y., Yamamoto, K., Sato, T., and Yamashita, A.: 1994, Chem. Phys. Lett. $229,447$.

43. Hoppe, P., Strebel, R., Eberhardtt. Amari, S., and Lewis, R.S.: 1996, Science 272, 1314.

44. Hudgins, D.M., Sandford, S.A., Allamandola, L.J., and Tielens, A.G.G.M.: 1993, Astron. Astrophys. Suppl. 86, 713.

45. Jäger, C., Mutschke, H., Begemann, B., Dorschner, J., and Henning, Th.: 1994, Astron. Astrophys. Suppl. $94,641$.

46. Jenneskins, P., Baratia, G.A., Kouchi, A., de Groot, M., Greenberg, J.M., and Strazzulla, G.: 1993, Astron. Astrophys. $273,583$.

47. Jenniskens, P. and Blake, D.F.: 1994, Science 265, 753.

48. Jenniskens, P., Blake, D.F., Wilson, M.A., and Pohorille.: 1995, Astrophys. J. 455, 389.

49. Kaito, C., Nakamura, H., Sakamoto, T., Kimura, S., Shiba, N., Yoshimura, Y., Nakayama, Y., Saito, Y., and Koike, C.: 1995, Planet. Space. Sci. 43, 1271.

50. Kawada, M., Bock, J.J., Hristov, V.V., Lange, A.E., Matsuhara, H., Matsumoto, T., Matsuura, S., Manskopf, P.D. Richards, P.L., and Tanaka, M.: 1994, Astrophys. J. 425, L89.

51. Khare, B.N., Thompson, W.R., Cheung, L., Chyba, C., Sagan, C., Arawaka, E.T., Meisse, C., and Tuminello, P.S.: 1993, Icarus 103, 290.

52. Kim, S.H. and Martin, P.G.: 1994, Astrophys. J. 431, 783.

53. Knapp, G.R., Sandell, G., and Robson, E.I.: 1993, Astrophys. J. Suppl. 88, 173.

54. Koike, C., Hasegawa, H., Asada, N., and Hattori, T.: 1993, Astrophys. Space Sci. 79, 77.

55. Krătschmer, W.: 1993, J. Chem. Soc. Faraday Trans. 89, 2285.

56. Leach, S.: 1995, in The Diffuse Interstellar Bands, ed. T.P. Snow and A.G.G.M. Tielens, (Kluwer, Dordrecht), pp 281 305.

57. Lee, W. and Wdowiak, T.J.: 1993, Astrophys. J, 417, L49.

58. Lee, W. and Wdowiak, T.J.: 1993, Astrophys. J. 410, L127.

59. Lee, W. and Wdowiak, T.J.: 1994, Molecules and Grains in Space: AIP Conf. Proc. $312,675$.

60. Levasseur-Regourd and Raulin, F.: 1995, Adv. Space. Res. 16 (2).

61. Liebman, S.A., Pesce-Rodriquez, R.A., and Mathews, C.N.: 1995, Adv. Space. Res. 15, 3 (71)

62. Marty, P., Serra, G., Chaudret, B., and Ristorcelli, I.: 1994, Molecules and Grains in Space: AIP Conf. Proc. $312,183$.

63. Matthews, C.N.: 1995, Planet. Space. Sci. 43, 1365.

64. Mathis, J.S.: 1994, Astrophys. J. 422, 176.

65. Maurette, M., Immel, G., Hammer, C., Harvey, R., Kurat, G., and Taylor, S.: 1994, Analysis of Interplanetary Dust, A.I.P. Conf. Proc. 310, 277.

66. Maurette, M., Brack, A., Engrand, C., Kurat, G., Leach, S., and Perreau, M.: 1994, Meteoritics 29, 498.

67. Maurette, M., Engrand, C., Brack, A., Kurat, G., Leach, S., and Perreau, M.: 1995, Lunar Planet, Sci. 26, 913.

68. Menella, V., Colangeli, L., Bussoletti, E., Merluzzi, P., Monaco, G., Palumbo, P., and Rotundi, A.: 1995, Planet. Space. Sci. 43, 1217.

69. Menella, V., Colangeli, L., and Bussoletti, E.: 1995, Astron. Astrophys. 295, 165.

70. Menella, V., Colangeli, L., Blanco, ., Bussoletti, E., Fonti, S., Merluzzi, Palumbo, P., and Rotundi, A.: 1995, Astrophys. J. 444, 288.

71. Menella, V., Colangeli, I., Bussoletti, E., Monaco, G., Palumbo, P., and Rotundi, A.: 1995, Astrophys. J. Suppl. 100, 149.

72. Merluzzi, P., Bussoletti, R., Dall'Oglio,G., and Piccirillo, L: 1994, Astrophys. J. 436, 286.

73. Millar, T.J. and Williams, D.A. (eds.): 1993, Dust and Chemistry in Astronomy, (IOP, Bristol). 
74. Millar, T.J. and Raga, A.C. (eds.): 1995, Shocks in Astrophysics, (Kluwer, Dordrecht).

75. Millar, T.J., MacDonald, G.H., and Habing, R.J.: 1995, Mon. Not. R. Astron. Soc. 273, 25.

76. Moore, M.H. and Hudson, R.L.: 1994, Astrophys. J. Suppl. 103, 45.

77. Moravec, Z. and Vanysek, V: 1994, Molecules and Grains in Space: AIP Conf. Proc. 312, 239.

78. Nenner, I. (ed.): 1994, Molecules and Grains in Space: AIP Conf. Proc. 312, pp.1-863.

79. Ott, U.: 1993, Nature 364, 25.

80. Papoular, R., Breton, J., Gerstenhium, G., Nenner, I., Papoular, R.J., and Pireaux, J.J.: 1993, Astron. Astrophys. 270, L5.

81. Papoular, R., Ellis, K., Guillois, O., Reynaud, C., and Nenner, I.,: 1993, J. Chem. Soc. Faraday Trans. 89, 2289.

82. Papoular, Guillois, O., Nenner, I., Perrin, J.M., Reynaud, C., and Sivan, J.P.: 1995, Planet. Space. Sci. 43, 1287.

83. Pendleton, Y.J.: 1995, Planet. Space. Sci. 43, 1359.

84. Pendleton, Y.J., Sandford, S.A., Allamandola, L.J., Tielens, A.G.G.M., and Sellgren, K: 1994, Astrophys. J. 437, 683.

85. Pollack, J.B., Hollenbach, D., Beckwith S., Simonelli, D.P., Roush, T., and Fong, W.: 1994, Astrophys. J. $421,615$.

86. Preibisch, T.H., Ossenkopf, V., Yorke, H.W., and Henning, Th.: 1993, Astron. Astrophys. 279, 577.

87. Reach, W.T. et al.: 1995, Astrophys. J. 451188.

88. Roush, T.L.: 1995, Planet. Space. Sci. 43, 1297.

89. Saito, Y., Kaito, C., Sakamoto, S., Nakayama, Y., and Koike, C.: 1995, Planet. Space. Sci. 43, 1303.

90. Sakata, A., Wada, S., Tokunaga, A.T., and Narisawa, T.: 1995, Planet. Space. Sci. 43, 1223.

91. Sakata, A., Wada, S., Tokunaga, A.T., Narisawa, T, Nagakawa, H., and Ono, H.: 1994, Astrophys. J. $430,311$.

92. Salama, F. and Allamandola, L.J.: 1993, J. Chem. Soc. Faraday Trans. 89, 2277.

93. Salama, F., Joblin, C., and Allamandola, L.J.: 1995, Planet. Space. Sci. 43, 1165.

94. Sandford, S.A. and Allamandola, L.J.: 1993, Astrophys. J. 409, L68.

95. Sandford, S.A., Pendleton, Y.J., and Allamandola, J..J.: 1995, Astrophys. J., 440, 697.

96. Schermann, C., Gough, S.F., Pichou, F., Landau, M., Hall, R.l., and Cadez, L.: 1994, Molecules and Grains in Space: AlP Conf. Proc. 312, 801.

97. Schmitt, B.: 1994, Molecules and Grains in Space: AIP Conf. Proc. 312, 735.

98. Schutte, W.A. and Gerakines, P.A.: 1995, Planet. Space. Sci. 43, 1253.

99. Schutte, W.A., Gerakines, P.A., Geballe, T.R., and van Dishoek, E.F.: 1995, Astron. Astrophys. (in press).

100. Schutte, W.A., Gerakines, P.A., van Dishoek, E.F., Greenberg, J.M., and Geballe, T.R.: 1994, Molecules and Grains in Space: AIP Conf. Proc. 312, 81.

101. Sedlmayr, E.: 1994, in IAU Colloquium 146: Molecules in the Stcllar Environment, Jorgensen, U. (ed.), (Springer-Verlag), pp. $163-185$

102. Shalabiea, O. and Greenberg, J.M.: 1994, Molecules and Grains in Space: AIP Conf, Proc. 312, 767.

103. Shipman, R.F. and Clark, F.O.: 1994, Astrophys. J. 422, 153.

104. Smoot, G.F.: 1995, Planet. Space. Sci. 43, 1345.

105. Stephens, J.R., Blanco, A., Bussoletti, E., Colangeli, L., Fonti, S., Mennella, V., and Orofino, V.: 1995, Planet. Space. Sci. 43, 1241.

106. Strazzulla, G., Castorina, A.C., and Palumbo, M.E.: 1995, Planet. Space. Sci. 43, 1247.

107. Taylor, S.D.: 1994, Molecules and Grains in Space: AIP Conf. Proc. 312, 81.

108. Tegler, S.C., Weintraub, D.A., Rettig, T.O., Pendleton, Y.J., Whittet, C.B., and Kulesa, C.A.: 1995, Astrophys. J. 439 , 279.

109. Thaddeus, P.: 1994, Molecules and Grains in Space: AIP Conf. Proc. 312, 711.

110. Thompson, S.P., Evans, A., and Jones, A.P.: 1996, Astron. Astrophys. 308, 309.

111. van der Hoek, B.: 1994, Molecules and Grains in Space: AIP Conf. Proc. 312, 173.

112. Watt, G.D. and Williams, P.M. (eds.): 1995, Circumstellar Matter, (Kluwer, Dordrecht).

113. Westley, M.S., Baragiola, R.A., Johnson, R.E., and Baratta, G.A.: 1995, Planet. Space. Sci. 43, 1311.

114. Whittet, D.B., Gerakines, P.A., Carkner, A.L., Hough, J.H., Martin, P.G., Prusti, T., and Kilkenny, D.: 1994, Mon.

Not. R. Astron. Soc. 268, 1.

115. Willacy, K. and Williams, D.A.: 1993, Mon. Not. R. Astron. Soc. 260, 635.

116. Willacy, K., Rawlings, J.M.C., and Williams, D.A.: 1994, Mon. Not. R. Astron. Soc. 269, 921.

117. Willacy, K., Williams, D.A., and Duley, W.W.: 1994, Mon. Not. R. Astron. Soc. 267, 949.

118. Williams, D.A.: 1994, Contemporary Physics 35, 269.

119. Zavagno, A. and Baluteau, J.P.: 1995, Planet. Space. Sci. 43, 1329. 